\title{
Sodium Current in Rat and Cat Thalamocortical Neurons: Role of a Non-Inactivating Component in Tonic and Burst Firing
}

\author{
H. Rheinallt Parri and Vincenzo Crunelli \\ Physiology Unit, School of Molecular and Medical Biosciences, University of Wales Cardiff, Cardiff CF1 3US, \\ United Kingdom
}

The properties of the $\mathrm{Na}^{+}$current present in thalamocortical neurons of the dorsal lateral geniculate nucleus were investigated in dissociated neonate rat and cat neurons and in neurons from slices of neonate and adult rats using patch and sharp electrode recordings.

The steady-state activation and inactivation of the transient $\mathrm{Na}^{+}$current $\left(I_{\mathrm{Na}}\right)$ was well fitted with a Boltzmann curve (voltage of half-maximal activation and inactivation, $V_{1 / 2},-29.84$ $\mathrm{mV}$ and $-70.04 \mathrm{mV}$, respectively). Steady-state activation and inactivation curves showed a small region of overlap, indicating the occurrence of a $I_{\mathrm{Na}}$ window current. $I_{\mathrm{Na}}$ decay could be fitted with a single exponential function, consistent with the presence of only one channel type.

Voltage ramp and step protocols showed the presence of a noninactivating component of the $\mathrm{Na}^{+}$current $\left(I_{\mathrm{NaP}}\right)$ that activated at potentials more negative $\left(V_{1 / 2}=-56.93 \mathrm{mV}\right)$ than those of $I_{\mathrm{Na}}$. The maximal amplitude of $I_{\mathrm{NaP}}$ was $\sim 2.5 \%$ of $I_{\mathrm{Na}}$,

The thalamocortical loop has been the subject of many electrophysiological studies because of its central role in awareness and sleep (Ribary et al., 1991; Steriade et al., 1993; Sillito et al., 1994; Barth and MacDonald, 1996) as well as in a number of neurological disorders (Malafosse et al., 1994; Jeanmonod et al., 1996). In particular, the ionic currents of its constituent neurons have been investigated extensively to determine their contribution to different electrophysiological behaviors (Steriade et at., 1990; Huguenard and Prince, 1991; Llinás et al., 1991; Connors, 1994; McCormick and Bal, 1997). A surprisingly noticeable exception, however, has been the transient $\mathrm{Na}^{+}$current $\left(I_{\mathrm{Na}}\right)$. Although thoroughly characterized in cortical pyramidal neurons during both developmental and pathological states (Huguenard et al., 1988; Fleidervish et al., 1996), there has been no study aimed at investigating the biophysical properties of this current in, and its precise contribution to the tonic and burst firing of, thalamocortical (TC) neurons. Thus, biophysical modeling of TC neurons (McCormick and Huguenard, 1992; Tóth and Crunelli, 1992; Destexhe et al., 1993; Antal et al., 1996) has relied on the modified description of $\mathrm{Na}^{+}$currents from squid axons and sympathetic, neocortical, and hippocampal neurons (French et al.,

Received July 18, 1997; revised Nov. 6, 1997; accepted Nov. 12, 1997.

The work was supported by the Wellcome Trust (Grant 37089). We thank Mr. D. W. Cope, Dr. G. Erdemli, and Dr. N. Leresche for expert advice and assistance during the course of this study, Dr. T. I. Tóth for helpful comments on this manuscript, and Mr. T. Gould for invaluable technical expertise.

Correspondence should be addressed to Vincenzo Crunelli, Physiology Unit, School of Molecular and Medical Biosciences, University of Wales Cardiff, Museum Avenue, Cardiff CF1 3US, UK.

Copyright (C) 1998 Society for Neuroscience $\quad 0270-6474 / 98 / 1810854-14 \$ 05.00 / 0$ thus significantly greater than the calculated contribution $(0.2 \%)$ of the $I_{\mathrm{Na}}$ window component. Comparison of results from dissociated neurons and neurons in slices suggested a dendritic as well as a somatic localization of $I_{\mathrm{NaP}}$. Inclusion of papain in the patch electrode removed the fast inactivation of $I_{\mathrm{Na}}$ and induced a current with voltage-dependence $\left(V_{1 / 2}=\right.$ -56.92) and activation parameters similar to those of $I_{\mathrm{NaP}}$.

Current-clamp recordings with sharp electrodes showed that $I_{\text {NaP }}$ contributed to depolarizations evoked from potentials of approximately $-60 \mathrm{mV}$ and unexpectedly to the amplitude and latency of low-threshold $\mathrm{Ca}^{2+}$ potentials, suggesting that this noninactivating component of the $\mathrm{Na}^{+}$channel population plays an important role in the integrative properties of thalamocortical neurons during both tonic and burst-firing patterns.

Key words: thalamus; action potential; persistent $\mathrm{Na}^{+}$current; inactivation; burst firing; dorsal lateral geniculate nucleus

1990; Belluzzi and Sacchi, 1991; Traub and Miles, 1991; Traub et al., 1991), a less than optimal compromise in view of the existence of voltage-dependent $\mathrm{Na}^{+}$channel isoforms with different biophysics, pharmacology, and tissue distribution (Noda et al., 1986; Heinemann et al., 1992; Roy and Narahashi, 1992).

Recently, a renewed interest in the noninactivating $\mathrm{Na}^{+}$current $I_{\mathrm{NaP}}$ has developed. This sustained component of the $\mathrm{Na}^{+}$ current is seen in many excitable cells, including central neurons (French et al., 1990; Alzheimer et al., 1993; Crill, 1996; Fleidervish and Gutnick, 1996), and it has been implicated in signal amplification (Stuart and Sakmann, 1995; Lipowsky et al., 1996) and intrinsic high frequency oscillations of neocortical neurons (Llinás et al., 1991; Silva et al., 1991). The mechanism or identity of $I_{\mathrm{NaP}}$ is still a matter of some controversy, with multiple theories being advanced in different systems (Alzheimer et al., 1993; Sugimori et al., 1994; Crill, 1996). Indirect evidence for the presence of $I_{\mathrm{NaP}}$ in mammalian TC neurons is limited to the effect of TTX in current-clamp recordings (Jahnsen and Llinás, 1984b; Tennigkeit et al., 1996; Pedroarena and Llinás, 1997). A description of the steady-state and kinetic properties of $I_{\mathrm{NaP}}$ in these neurons would be significant for a fuller understanding of their signal integration properties in physiological functions and neurological conditions and would also provide the necessary data for ongoing simulation studies of the activity of single and small networks of thalamic neurons.

In this study we have determined the properties of $I_{\mathrm{Na}}$ and $I_{\mathrm{NaP}}$ in TC neurons using patch-clamp recordings in the dorsal lateral geniculate nucleus (dLGN) of neonate rats and cats and adult rats, and we have investigated the physiological role of $I_{\mathrm{NaP}}$ in 
tonic and burst firing using current-clamp microelectrode recordings in adult rats.

A preliminary report of some of these results has been published previously (Parri et al., 1996).

\section{MATERIALS AND METHODS}

\section{Preparations}

Neonate rat. Slices containing the dLGN were obtained from male Wistar rats as described by Leresche (1992). Briefly, 7- to 11-d-old rats were anesthetized with halothane $(2 \%)$ and decapitated. The brain was removed, a block of tissue containing the dLGN was separated from the rest of the brain, and 350- $\mu$ m-thick slices were prepared from this tissue block using a vibratome (Energy Beam Science). Dissection and slicing procedures were performed in ice-cold medium of the following composition (in mM): $\mathrm{NaCl} 120, \mathrm{KCl} 2, \mathrm{MgCl}_{2}$ 4, PIPES 20, $\mathrm{CaCl}_{2} 1$, glucose 25 , ascorbic acid 0.3 , kynurenic acid $1, \mathrm{pH} 7.35$ with $\mathrm{NaOH}$. All chemicals were obtained from Sigma (St. Louis, MO) unless stated otherwise. Slices were stored in an oxygenated $\left(100 \% \mathrm{O}_{2}\right)$ storage bath until recording commenced. After at least $1 \mathrm{hr}$, one slice was then anchored in the recording chamber by use of nylon threads fixed across a platinum harp and perfused continuously with the required recording solution (see below).

Dissociated neurons were prepared according to the procedure described by Hernandez-Cruz and Pape (1989), Budde et al. (1992), and Oh et al. (1995). Briefly, slices from neonate rats were prepared as detailed above and treated with $3 \mathrm{mg} / \mathrm{ml}$ protease XXIII for 25-40 min in a glass chamber of design similar to that described by Kay and Wong (1986) Neurons were triturated in $\mathrm{Ca}^{2+}$-free Ringer's solution using firepolished Pasteur pipettes of decreasing tip diameter. Dissociated neurons were then plated onto coverslips coated with $1 \mathrm{mg} / \mathrm{ml}$ poly-D-lysine and allowed to settle for $\sim 5$ min before recording commenced.

Adult rat. Slices were prepared as described previously (Crunelli et al., 1987; Williams et al., 1996). Briefly, male Wistar rats (150-200 gm) were anesthetized ( $2 \%$ halothane) and decapitated. A block of tissue containing the thalamus was dissected, and $400-\mu \mathrm{m}$-thick slices containing the dLGN were cut using a vibroslicer (Campden Instruments). All dissection and slicing procedures were performed in ice-cold medium of the following composition (in mM): $\mathrm{NaCl} 134, \mathrm{NaHCO}_{3} 16, \mathrm{KCl} 5, \mathrm{KH}_{2} \mathrm{PO}_{4}$ $1.25, \mathrm{MgSO}_{4} 5, \mathrm{CaCl}_{2}$, and glucose 10 . Slices were maintained at room temperature in this Ringer's solution and bubbled with a $95 \% \mathrm{O}_{2}, 5 \%$ $\mathrm{CO}_{2}$ mixture.

Neonate cat. Cats (7-10 d old) were anesthetized (1\% halothane, $2 \%$ $\mathrm{N}_{2} \mathrm{O}$ ), and the brain was removed as described previously (Pirchio et al., 1997). From a block of tissue containing the dLGN, 400- $\mu \mathrm{m}$-thick slices were prepared in ice-cold medium (see above) using a Campden vibroslicer, and dissociated neurons were then produced using the same methods as described above for the neonate rat.

\section{Electrophysiology}

Patch-clamp recordings of identified neurons. The slice or the coverslip containing the dissociated neurons was placed in a recording chamber mounted on the stage of a Nikon Axiophot microscope. TC neurons were identified, and were distinguishable from interneurons, by their characteristic size (soma diameter: 20-30 $\mu \mathrm{m}$ ) and multipolar morphology (Hernandez-Cruz and Pape, 1989; Leresche, 1992; Williams et al., 1996). Membrane currents were recorded at room temperature $\left(18-22^{\circ} \mathrm{C}\right)(\mathrm{ex}-$ cept those from adult rat slices, see below) using an Axopatch 200A (Axon Instruments, Foster City, CA). Patch electrodes were pulled from borosilicate glass (GC120F, Clark Electromedical Instruments, Pangbourne, UK) using a horizontal electrode puller (Sutter Instruments, Novato, CA) and had resistances of 1-4 M $\Omega$ when filled with CsF internal solution. Electrodes were coated with Sylgard (Corning, Corning, NY) to counteract electrode capacitance artifacts. Series resistances $(4-10 \mathrm{M} \Omega)$ were compensated $(60-80 \%)$ using the compensatory circuits of the amplifier, and data were not used for analysis if the calculated maximum uncompensated error was $\geq 5 \mathrm{mV}$. Voltage protocols, data acquisition, and analysis were controlled with pClamp (Axon Instruments). Currents were sampled at $40 \mathrm{kHz}$ and filtered with a low-pass Bessel filter at $5 \mathrm{kHz}$. Membrane capacitance was measured using the capacitance compensation circuitry. Currents were corrected on line for linear leakage and capacitative current by scaling the averaged response to four hyperpolarizing steps of $5 \mathrm{mV}$ amplitude obtained at a holding potential of $-100 \mathrm{mV}$.

Blind patch-clamp recordings. In slices of adult rat dLGN, voltage ramp recordings of $I_{\mathrm{NaP}}$ were performed at $35 \pm 1^{\circ} \mathrm{C}$ using an Axopatch 1D amplifier (Axon Instruments) and pClamp. Series resistance in these experiments was $17 \pm 1 \mathrm{M} \Omega(n=4)$.

Recording solutions. For $\mathrm{Na}^{+}$current characterization, the internal pipette solution contained (in mM): CsF 120, HEPES 10, EGTA 10, $\mathrm{MgCl}_{2} 2, \mathrm{CaCl}_{2} 1, \mathrm{Na}_{2} \mathrm{ATP} 4$, GTP $0.5, \mathrm{pH} 7.3$ with TEA-OH (Aldrich, Milwaukee, WI); osmolarity was adjusted to $290 \mathrm{mOsm}$. The standard extracellular recording solution with physiological levels of $\mathrm{Na}^{+}$and the $\mathrm{K}^{+}$and $\mathrm{Ca}^{2+}$ channel blockers contained (in mM): $\mathrm{NaCl} 120$, sodium HEPES $16, \mathrm{KCl}$, glucose 10, TEA-Cl 20, $\mathrm{CaCl}_{2} 1$, 4-aminopyridine 2, $\mathrm{MgCl}_{2} 4, \mathrm{NiCl}_{2} 0.5, \mathrm{CdCl}_{2} 0.1, \mathrm{pH} 7.4$; osmolarity was adjusted to 300 mOsm. Steady-state and kinetic experiments on $I_{\mathrm{Na}}$ were performed with a reduced extracellular $\mathrm{Na}^{+}$concentration $(20 \mathrm{mM})$ to decrease the amplitude of the current and so minimize the impact of possible series resistance-induced errors. All experiments in neonate cats were performed in $30 \mathrm{~mm}$ extracellular $\mathrm{Na}^{+}$. The osmolarity of these solutions was maintained at $300 \mathrm{mOsm}$ by increasing the TEA-Cl concentration. In blind patch-clamp experiments in adult slices, $\mathrm{NaHCO}_{3}$ replaced sodium HEPES as the buffer in the bathing solution.

Current-clamp recordings. For sharp electrode current-clamp recordings, adult dLGN slices were placed in an interface-type chamber and continuously perfused with a warmed $\left(35 \pm 1^{\circ} \mathrm{C}\right)$, oxygenated $\left(95 \% \mathrm{O}_{2}\right.$, $5 \% \mathrm{CO}_{2}$ ) medium containing (in $\mathrm{mM}$ ): $\mathrm{NaCl} 134, \mathrm{NaHCO}_{3} 16, \mathrm{KCl} 2$, $\mathrm{KH}_{2} \mathrm{PO}_{4} 1.25, \mathrm{MgSO}_{4} 1, \mathrm{CaCl}_{2} 2$, and glucose 10 . Intracellular electrodes contained $1 \mathrm{M}$ potassium acetate, recordings were performed using an Axoclamp 2A, and current and voltage records were stored on a Biologic DAT recorder (Intracel Ltd, Royston, UK). Some of these experiments were performed in the presence of 4-( $N$-ethyl- $N$ phenylamino)-1,2-dimethyl-6-(methylamino)pyrimidinium chloride (ZD 7288) (kindly donated by Dr. P. Marshall, Zeneca, Macclesfield, UK).

Data analysis. Data were analyzed using the Clampfit program of pClamp (Axon Instruments) and the mathematical transform and curve fitting routines of Sigma Plot (Jandel Scientific, San Rafael, CA). For the construction of steady-state activation and inactivation curves, maximal conductances were estimated using the relation $g=I /\left(V_{\mathrm{s}}-V_{\text {rev }}\right)$, where $I$ is the measured current, $V_{\mathrm{s}}$ the voltage step, and $V_{\mathrm{rev}}$ the measured current reversal potential. Estimated conductances were normalized and plotted against step potential. Individual traces were fitted in Clampfit using the Chebyshev algorithm to single exponentials of the form $y=$ $a e^{\text {-bt }}$. Data points were fitted with Boltzmann curves of the form $y=1 /(1$ $\left.+\mathrm{e}^{(\mathrm{V} 1 / 2-\mathrm{V}) / \mathrm{k}}\right)$ (where $V_{1 / 2}$ is the voltage of half-maximal activation, $k$ is the steepness constant), single exponentials of the form $y=1-a e^{\mathrm{bt}}$, and double exponentials of the form $y=1-a e^{\mathrm{bt}}+c e^{\mathrm{dt}}$. All potential values quoted in the text and figures have been corrected for liquid junction potentials (Barry and Lynch, 1991; Neher, 1992): -11 and $-8 \mathrm{mV}$ for low $(20 \mathrm{~mm})$ and high $(130 \mathrm{~mm}) \mathrm{Na}^{+}$solution, respectively, calculated using Axoscope (Axon Instruments). All quantitative data in the text and figures are expressed as mean \pm SEM unless stated otherwise, and statistical significance was tested using Student's $t$ test.

\section{RESULTS}

The data presented in this paper are based on the following preparations: dissociated neurons $(n=45)$ from neonate rat, dissociated neurons $(n=7)$ from neonate cat, neurons $(n=18)$ in slices of neonate rats, and neurons $(n=14)$ in slices of adult rats.

\section{Steady-state activation and inactivation}

The kinetic and steady-state properties of $I_{\mathrm{Na}}$ were determined using acutely dissociated neurons from neonate rats, which enabled a better space clamp because of the lack of an extensive dendritic arborization. In these experiments the extracellular $\mathrm{Na}^{+}$concentration was also reduced to $20 \mathrm{~mm}$ to decrease the amplitude of the current and further reduce voltage disparities introduced by series resistance errors. To study the activation of $I_{\mathrm{Na}}$, neurons were clamped at a holding potential of $-111 \mathrm{mV}$, and depolarizing voltage steps of increasing amplitude were delivered every $3 \mathrm{sec}$. At potentials more positive than $-60 \mathrm{mV}$ the voltage steps elicited rapidly activating inward currents that inactivated within $10 \mathrm{msec}$ (Fig. $1 A_{1}$ ). The elicited currents reached a peak at $-23 \pm 0.5 \mathrm{mV}$ and reversed at $26.6 \pm 4.2 \mathrm{mV}(n=6)$ (Fig. 
$\mathrm{A}_{1}$
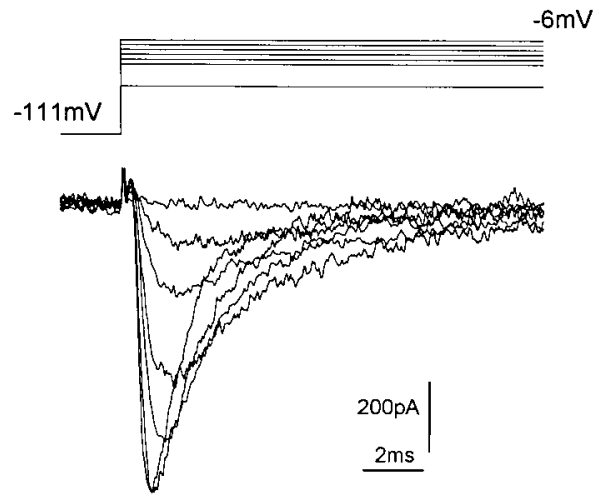

$\mathrm{A}_{2}$

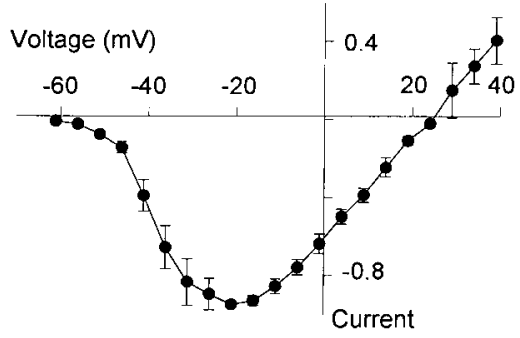

$\mathrm{A}_{3}$

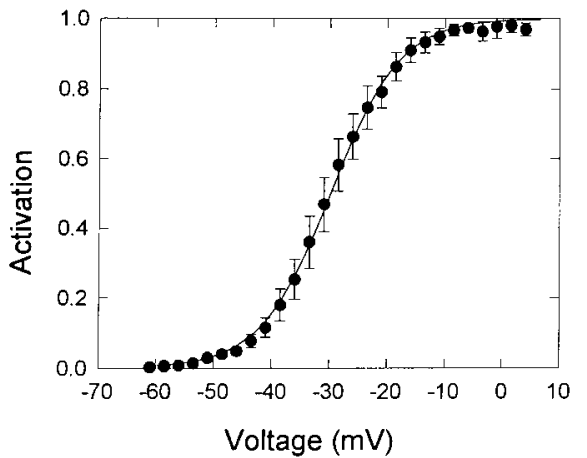

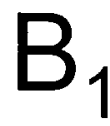
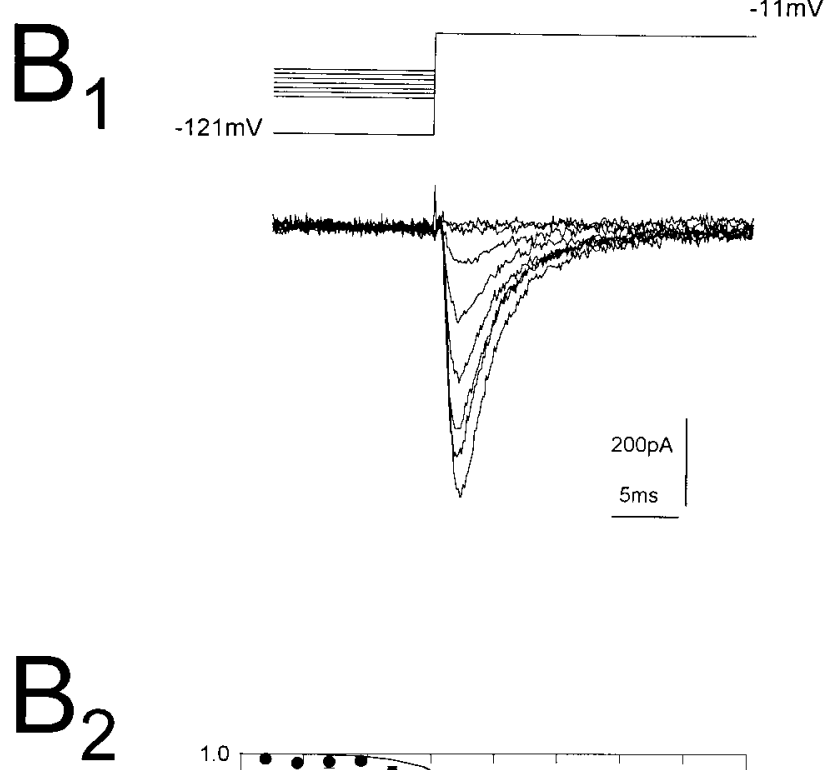

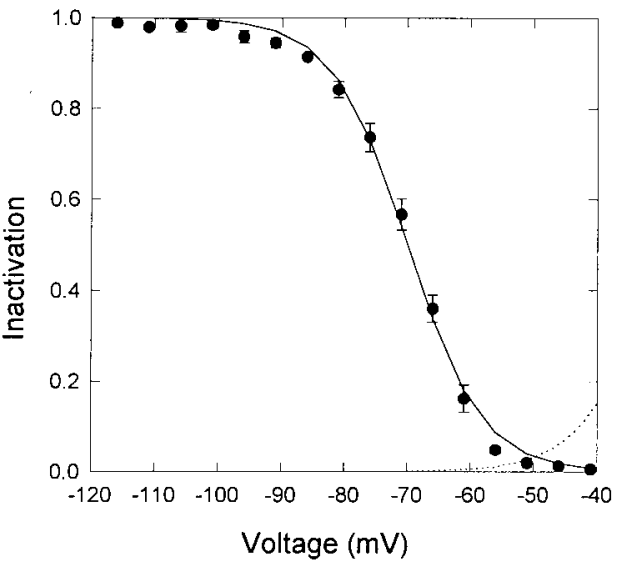

Figure 1. Steady-state properties of $I_{\mathrm{Na}} \cdot A_{1}$, Currents elicited with step depolarizations from a holding potential of $-111 \mathrm{mV}$ to potentials of between -61 and $-6 \mathrm{mV} . A_{2}$, Normalized current-voltage relation for $I_{\mathrm{Na}}(n=6)$. Currents from individual neurons were normalized to their maximum amplitude and then averaged. $A_{3}$, Steady-state activation of $I_{\mathrm{Na}}$ : normalized conductance values are plotted against step potential. The points $(n=6)$ are fitted with a single Boltzmann relation. $B_{1}$, Currents elicited by a step depolarization to $-11 \mathrm{mV}$ from holding potentials of between -121 and -46 $\mathrm{mV}$, to investigate $I_{\mathrm{Na}}$ inactivation (same neuron as in $A_{1}$ ). $B_{2}$, These currents were normalized to the current elicited from a holding potential of -121 $\mathrm{mV}$ and used to construct the steady-state inactivation. The plotted points $(n=6)$ are fitted with a single Boltzmann function. The dotted line is the Boltzmann curve fitted to $I_{\mathrm{Na}}$ activation $\left(A_{3}\right)$ to display the region of overlap between the steady-state activation and inactivation curves $\left(I_{\mathrm{Na}}\right.$ window current). All experiments were conducted in dissociated neonate rat neurons at room temperature.

$1 A_{2}$ ), a value close to the theoretically determined reversal potential of $23 \mathrm{mV}$. This result, together with the block by $1 \mu \mathrm{M}$ tetrodotoxin (TTX) (data not shown), defined this current as a TTX-sensitive neuronal $I_{\mathrm{Na}}$. The steady-state activation of $I_{\mathrm{Na}}$, constructed from six neurons, could be fitted with a single Boltzmann curve $\left(V_{1 / 2}=-29.84 ; k=5.88\right)$ (Fig. $\left.1 A_{3}\right)$. To compare $I_{\mathrm{Na}}$ activation in different conditions/species (see below) we also fitted the data of each neuron with a Boltzmann curve. From this analysis we obtained a $V_{1 / 2}$ of $-29.8 \pm 1.74 \mathrm{mV}$ and a $k=5.48 \pm$ $0.18(n=6)$ (Table 1$)$.

Inactivation was investigated using a protocol in which $I_{\mathrm{Na}}$ was elicited with voltage steps to $-11 \mathrm{mV}$ every $5 \mathrm{sec}$ from different holding potentials. $I_{\mathrm{Na}}$ was reduced when the holding potential was more positive than $-90 \mathrm{mV}$, and no current could be elicited from holding potentials more positive than $-40 \mathrm{mV}$ (Fig. $1 B_{1}$ ). The voltage dependence of steady-state inactivation was plotted by normalizing $I_{\mathrm{Na}}$ amplitude at different holding potentials to that elicited from a holding potential of $-121 \mathrm{mV}$. The resulting points (from six neurons) could be fitted with a single Boltzmann curve $\left(V_{1 / 2}=-70 ; k=5.88\right)\left(\right.$ Fig. $\left.1 B_{2}\right)$. Again, to compare $I_{\mathrm{Na}}$ inactivation in different conditions/species (see below) we also fitted the data of each neuron with a Boltzmann curve and obtained a $V_{1 / 2}=-70.04 \pm 0.76 \mathrm{mV}$ and a $k=5.8 \pm 0.15(n=$ 6) (Table 1). Analysis of the steady-state activation and inactivation curves indicated the presence of a small area of overlap in a voltage region centered around $-50 \mathrm{mV}$, thus predicting the existence of a "window component" of $I_{\mathrm{Na}}$ (Fig. $1 B_{2}$ ).

\section{Kinetics of fast activation and inactivation}

Because of the fast activation of $I_{\mathrm{Na}}$ and the uncertainty inherent in fitting such a rapid rising phase, the time to peak was taken as an indicator of the rate of current activation. Activation was 
Table 1. Activation and inactivation parameters

\begin{tabular}{|c|c|c|c|c|c|c|}
\hline \multirow[b]{2}{*}{ Parameter } & \multicolumn{4}{|c|}{ Neonate rat dissociated TC dLGN neurons } & \multicolumn{2}{|c|}{$\begin{array}{l}\text { Neonate cat dissociated TC dLGN } \\
\text { neurons }\end{array}$} \\
\hline & $\mathrm{I}_{\mathrm{Na}}$ activation & $\mathrm{I}_{\mathrm{Na}}$ inactivation & $\mathrm{I}_{\mathrm{NaP}}$ activation & $\mathrm{I}_{\text {papain }}$ activation & $\mathrm{I}_{\mathrm{Na}}$ activation & $\mathrm{I}_{\mathrm{Na}}$ inactivation \\
\hline$V_{1 / 2}$ & $\begin{aligned}-29.8 & \pm 1.74 \\
(n & =6)\end{aligned}$ & $\begin{aligned}-70.04 & \pm 0.76 \\
(n & =6)\end{aligned}$ & $\begin{array}{c}-53.87 \pm 3.05 \\
(n=4)\end{array}$ & $\begin{array}{c}-56.92 \pm 0.96 \\
(n=3)\end{array}$ & $\begin{array}{c}-27.82 \pm 2.7 \\
(n=5)\end{array}$ & $\begin{aligned}-65.93 & \pm 1 \\
(n & =5)\end{aligned}$ \\
\hline$k$ & $\begin{array}{c}5.48 \pm 0.18 \\
(n=6)\end{array}$ & $\begin{array}{l}5.8 \pm 0.15 \\
(n=6)\end{array}$ & $\begin{array}{c}8.57 \pm 1.89 \\
(n=4)\end{array}$ & $\begin{array}{c}6.31 \pm 0.56 \\
(n=3)\end{array}$ & $\begin{array}{l}6.71 \pm 0.25 \\
(n=5)\end{array}$ & $\begin{array}{c}5.92 \pm 0.25 \\
\quad(n=5)\end{array}$ \\
\hline
\end{tabular}

All experiments were performed at room temperature.
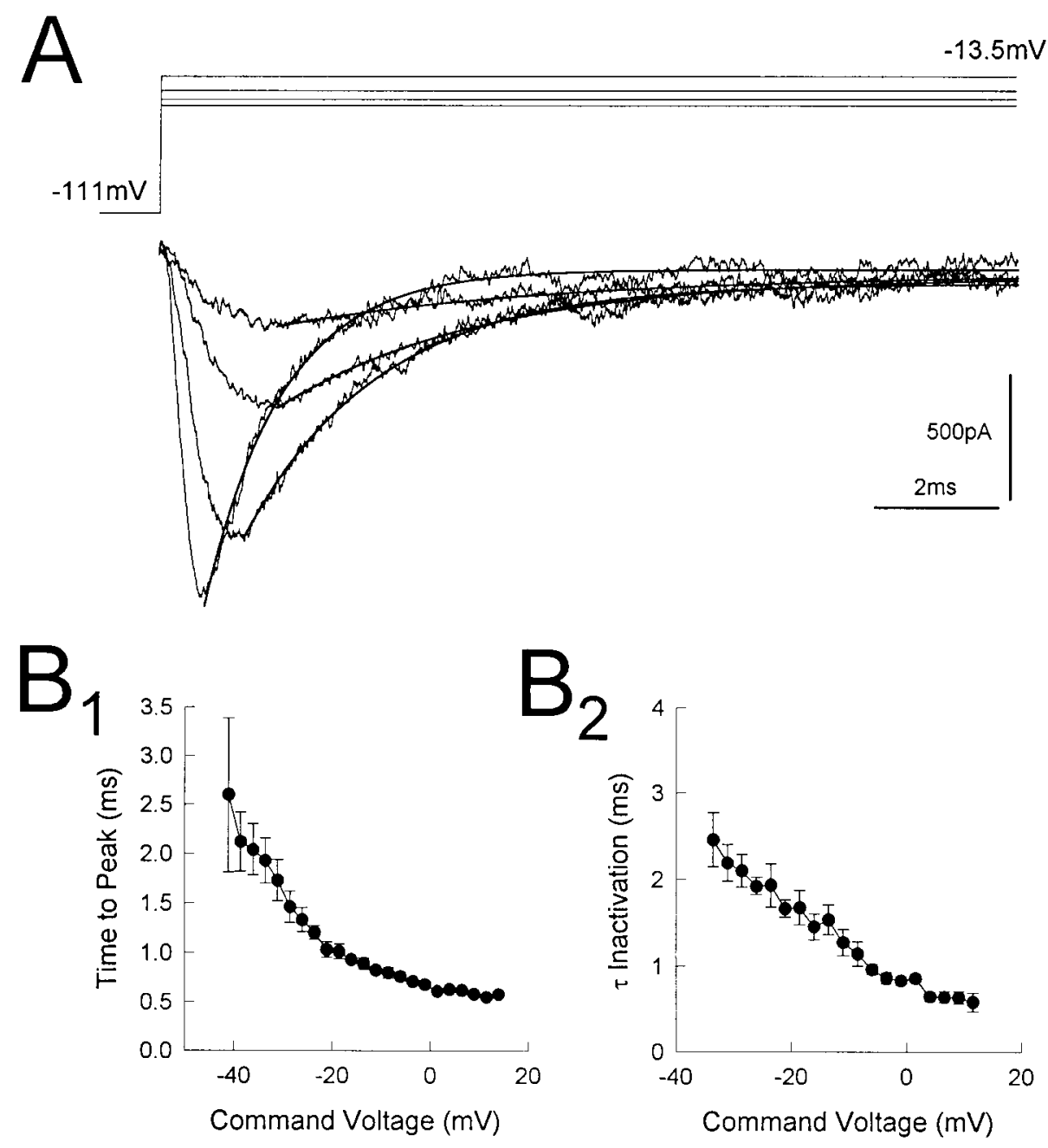

Figure 2. Fast activation and inactivation kinetics of $I_{\mathrm{Na}} \cdot A$, Single exponential decays of the form $1-\mathrm{e}^{\mathrm{ax}}$ well fitted the fast inactivation of $I_{\mathrm{Na}}$. Examples show fits of currents elicited by step depolarizations from $-111 \mathrm{mV}$ to -28.5 , $-26,-21$, and $-13.5 \mathrm{mV}$. $B_{1}$, Plot shows the time to current peak against step potential $(n=$ 4). $B_{2}$, Plot shows the $\tau$ of inactivation against step potential $\left(n=4\right.$; same cells as in $\left.B_{1}\right)$. Data are from dissociated neonate rat neurons at room temperature.

voltage dependent (Fig. $2 A, B_{1}$ ), with the time to peak decreasing from $2.59 \pm 0.79 \mathrm{msec}$ at $-41 \mathrm{mV}$ to $0.59 \pm 0.01 \mathrm{msec}$ at $9 \mathrm{mV}$ $(n=4)$ (Fig. $\left.2 B_{1}\right) . I_{\mathrm{Na}}$ decay could be fitted with a single exponential function (Fig. $2 A$ ) and was found to be voltage dependent, with a $\tau$ that ranged from $2.19 \pm 0.21 \mathrm{msec}$ at $-31 \mathrm{mV}$ to $0.64 \pm 0.07 \mathrm{msec}$ at $9 \mathrm{mV}(n=4)$ (Fig. $\left.2 B_{2}\right)$. The relationships of the time to peak and $\tau$ of inactivation against membrane potential could not be fitted with simple exponential functions. This finding is consistent with classic models of channel activation (Hodgkin and Huxley, 1952), so that our experimental data in the measured voltage range would be located on the downstroke region of bell-shaped curves.

\section{Onset of, and recovery from, inactivation}

The onset of $I_{\mathrm{Na}}$ inactivation at a particular potential will affect the action potential firing properties of the neuron, because it defines the rate at which the channel population enters an inactivated state. We investigated this process using a two-voltage step protocol. Neurons were held at a negative potential $(-108$ $\mathrm{mV})$, and $I_{\mathrm{Na}}$ was elicited by 10 -msec-long depolarizing steps to $-8 \mathrm{mV}$ (Fig. $3 A_{1}$ ). The onset of inactivation at $-68 \mathrm{mV}$ was determined by stepping to this potential for different durations before eliciting $I_{\mathrm{Na}}$. Times at the inactivating voltage were varied between 1 and $300 \mathrm{msec}$, with currents normalized to the $I_{\mathrm{Na}}$ 


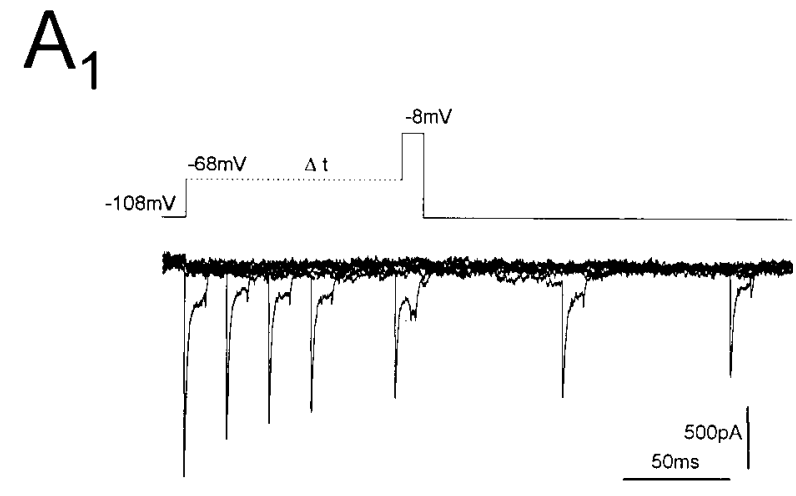

$\mathrm{A}_{2}$

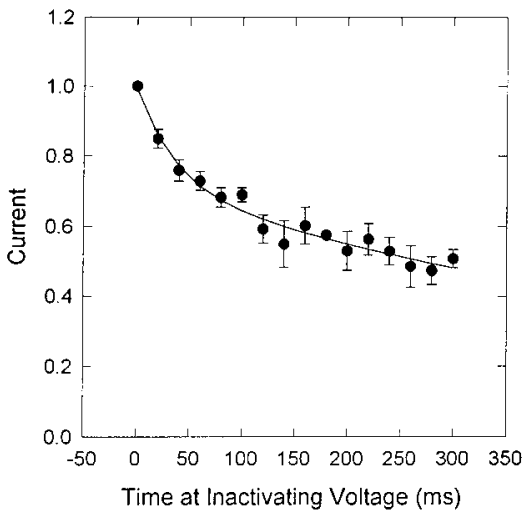

$\mathrm{B}_{1}$

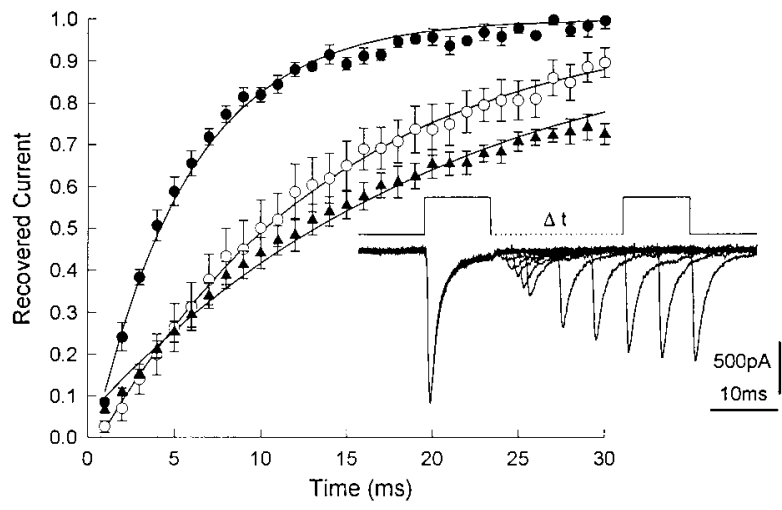

$\mathrm{B}_{2}$

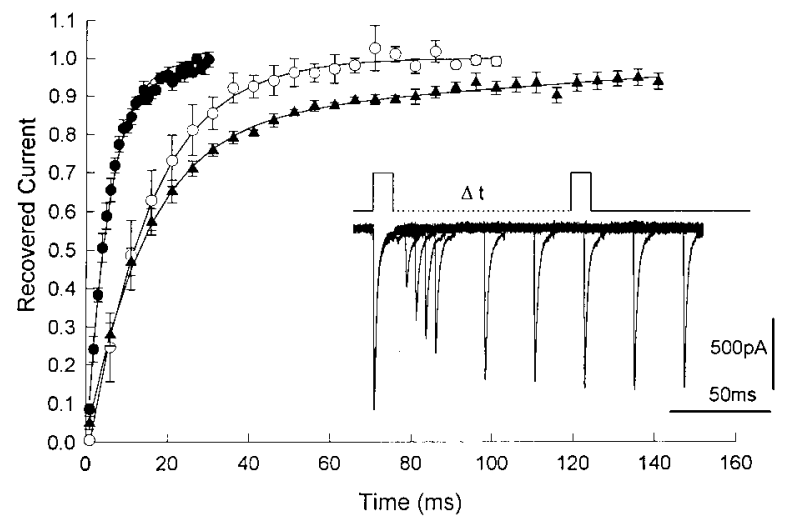

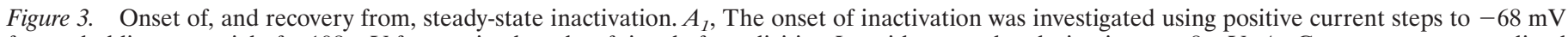

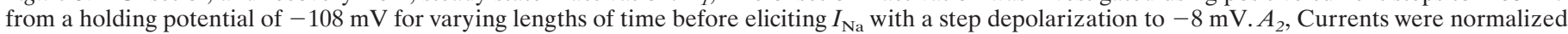

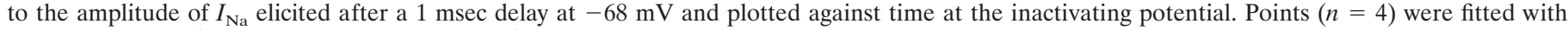

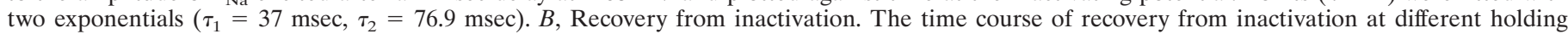

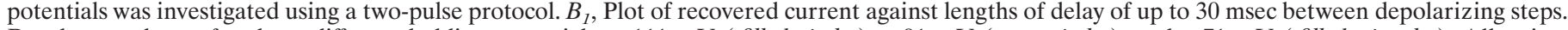

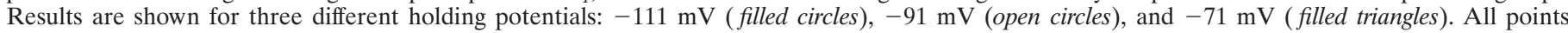

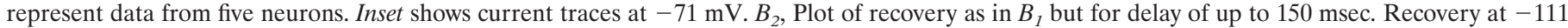

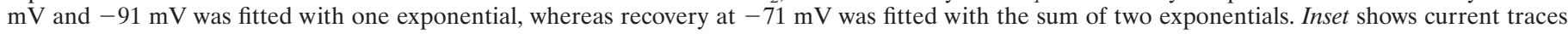

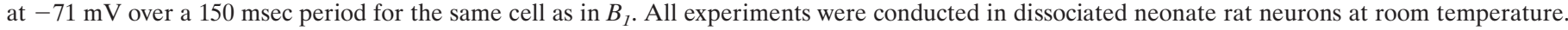

elicited after $1 \mathrm{msec}$ at $-68 \mathrm{mV}$. Analysis of these data showed that the onset of inactivation could be fitted with two exponentials with $\tau_{1}=37 \mathrm{msec}$ and $\tau_{2}=76.9 \mathrm{msec}$ (Fig. $3 A_{2}$ ).

The rate of recovery from inactivation also has fundamental implications for the frequency and robustness of repetitive firing properties and was investigated using a two-pulse protocol. $I_{\mathrm{Na}}$ was elicited with a $10 \mathrm{msec}$ depolarizing step to $-11 \mathrm{mV}$, during which the current was inactivated. A second test pulse was then delivered to elicit $I_{\mathrm{Na}}$, whereas the time between the two pulses $(\Delta t)$ was varied between 1 and $150 \mathrm{msec}$ to determine the rate of recovery. The experiment was repeated at different holding potentials to investigate the voltage dependence as well as the time course of recovery (Fig. 3B). We observed that fast recovery from inactivation, investigated by varying $\Delta t$ in $1 \mathrm{msec}$ steps between 1 and $30 \mathrm{msec}$, was well fitted by single exponential functions with $\tau=5.52 \mathrm{msec}$ and $\tau=13.88 \mathrm{msec}$ at holding potentials of -111 $\mathrm{mV}$ and $-91 \mathrm{mV}$, respectively. However, recovery at $-71 \mathrm{mV}$ was not well fitted with a single exponential (Fig. $3 B_{1}$ ). Recordings with longer $\Delta t$ durations showed that recovery was complete within 30 and $60 \mathrm{msec}$ at -111 and $-91 \mathrm{mV}$, respectively (Fig. $3 B_{2}$ ). At $-71 \mathrm{mV}$, however, recovery was not complete in 150 msec and was best fitted with two exponentials $\left(\tau_{1}=14.74 \mathrm{msec}\right.$ and $\tau_{2}=1.42 \mathrm{sec}$ ).

\section{$I_{\mathrm{Na}}$ in TC neurons of the cat dLGN}

Steady-state activation and inactivation of $I_{\mathrm{Na}}$ in dissociated cat neurons was studied using voltage protocols similar to those used in dissociated rat neurons (Fig. $4 A_{1}, A_{2}$ ). These data could be fitted with a single Boltzmann curve for activation $\left(V_{1 / 2}=-27.2\right.$; $k=7.59)$ and inactivation $\left(V_{1 / 2}=-65.7 ; k=5.82\right)$, respectively. Indeed, the parameters of the Boltzmann curves for $I_{\mathrm{Na}}$ activation in five cat neurons show no difference in $V_{1 / 2}(-27.82 \pm 2.7 \mathrm{mV})$ $(p=0.49)$ but a larger $k(6.71 \pm 0.25)(p<0.005)$ compared with the rat, whereas for the inactivation a slightly more depolarized $V_{1 / 2}(-65.93 \pm 1.0 \mathrm{mV})(p<0.05)$ but a similar $k(k=5.92 \pm$ $0.25)(p=0.686)$ were observed (Fig. $4 B)$ (Table 1$)$. The kinetic properties of $I_{\mathrm{Na}}$ in cat neurons were also similar to those in rat neurons and included, for example, a time to peak of $1.75 \pm 0.29$ msec and $0.76 \pm 0.05 \mathrm{msec}$ at -31 and $9 \mathrm{mV}$, respectively (Fig. $4 C_{1}$ ), and a $\tau$ of inactivation of $4.1 \pm 1.56 \mathrm{msec}$ and $1.67 \pm 0.27$ msec at -31 and $9 \mathrm{mV}$, respectively ( $n=5$, for all measurements) (Fig. $4 C_{2}$ ). 

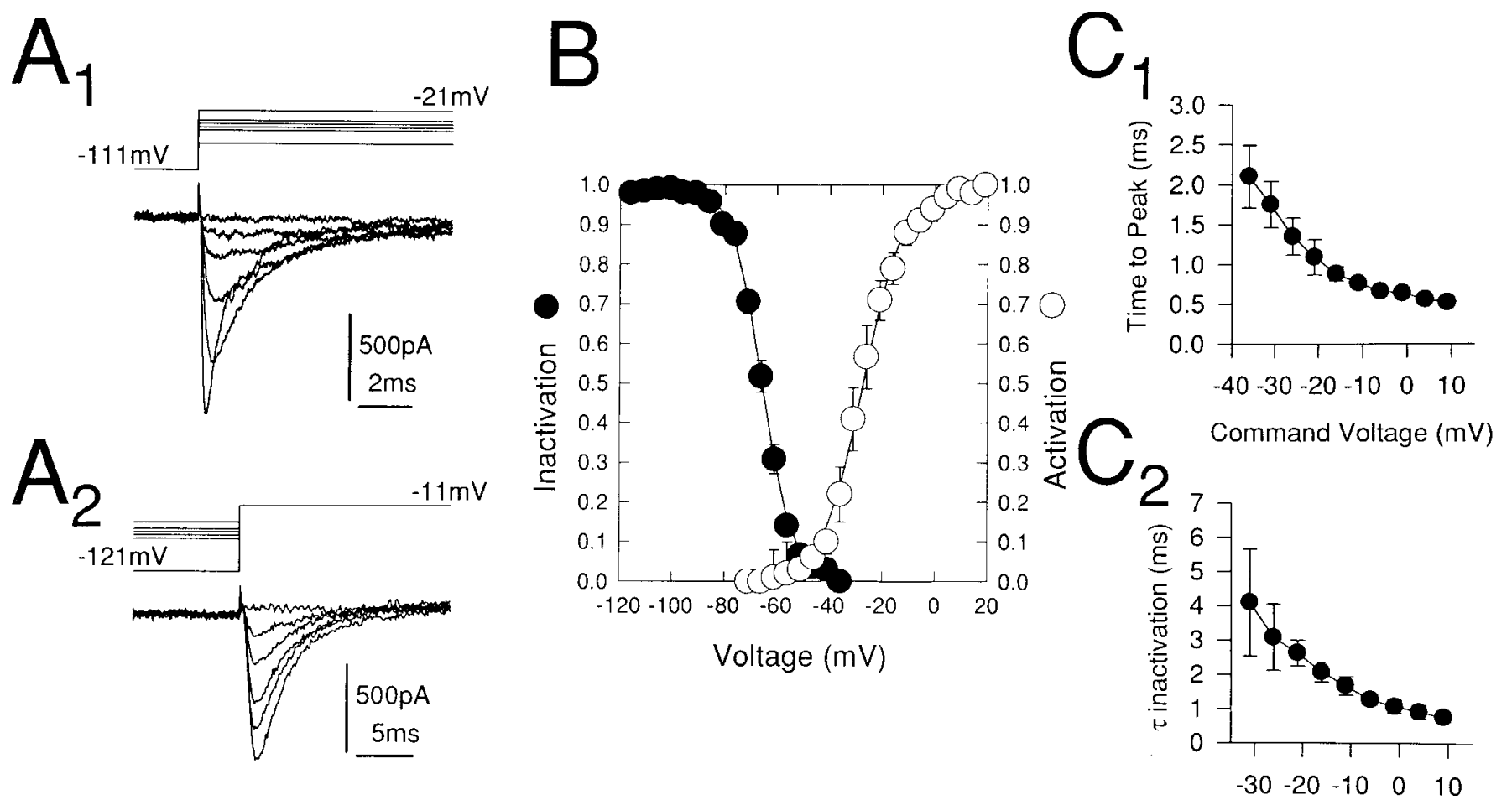

Command Voltage $(\mathrm{mV})$

Figure 4. Steady-state and kinetic properties of $I_{\mathrm{Na}}$ in dissociated neonate cat TC neurons at room temperature. $A_{1}$, Currents elicited from a holding potential of $-111 \mathrm{mV}$ to test potentials of between -71 and $-21 \mathrm{mV}$. $A_{2}$, Currents elicited by a voltage step to $-11 \mathrm{mV}$ from holding potentials of between -121 and $-35 \mathrm{mV}$. $B$, Steady-state activation and inactivation curves obtained from measurements in five neonate cat neurons were fitted with a single Boltzmann. Note the voltage dependence similar to the corresponding curves for the neonate rat neurons $\left(\right.$ Fig. $\left.1 A_{3}, B_{2}\right)$ and the presence of a window component. $C_{1}$, Plot shows the time to current peak against step potential $(n=5) . C_{2}$, Plot shows the $\tau$ of inactivation against step potential $(n=$ 5; same neurons as in $C_{1}$ ).

\section{$I_{\mathrm{NaP}}$ in dLGN TC neurons}

A persistent component $\left(I_{\mathrm{NaP}}\right)$ of the $\mathrm{Na}^{+}$current evoked by voltage step protocols could be observed by increasing the gain of the amplifier, so that $I_{\mathrm{Na}}$ was saturated. Both $I_{\mathrm{Na}}$ and $I_{\mathrm{NaP}}$ were blocked by TTX $(1 \mu \mathrm{M})(n=3)$ (Fig. $\left.5 A_{1}\right)$. A TTXsensitive $(n=3)$, slow component of the $\mathrm{Na}^{+}$current (i.e., $\left.I_{\mathrm{NaP}}\right)$ could also be seen when a voltage ramp from -100 to 50 $\mathrm{mV}$ was delivered at a rate of $0.2 \mathrm{mV} / \mathrm{msec}$ (Fig. $5 A_{2}$ ). Because the maximal amplitude of this current was relatively small $(\sim 100 \mathrm{pA})$, this and the following experiments were performed in extracellular solutions containing $130 \mathrm{mM} \mathrm{Na}^{+}$to determine the amplitude and properties of $I_{\mathrm{NaP}}$ under a physiological extracellular $\mathrm{Na}^{+}$concentration.

The activation range of $I_{\mathrm{NaP}}$ was investigated by applying long step depolarizations and measuring the amplitude of $I_{\mathrm{NaP}}$ at 60 msec into the depolarizing step, after $I_{\mathrm{Na}}$ relaxation (Fig. $5 B_{1}$ ). Recordings were performed at a high gain to enable reliable measurements of the sustained component. $I_{\mathrm{NaP}}$ activation began at approximately $-70 \mathrm{mV}$, peaked at $-39 \pm 2 \mathrm{mV}$, and had an extrapolated reversal potential of $4 \pm 6 \mathrm{mV}(n=4)$ (Fig. $\left.5 B_{2}\right)$. This reversal potential, however, is probably an underestimation of the true reversal potential, because at potentials more than $-10 \mathrm{mV}$ an outward current with properties similar to those described by Alzheimer (1994) in pyramidal neurons of the sensorimotor cortex was also activated. The activation of $I_{\mathrm{NaP}}$ could be well fitted with a Boltzmann curve (Fig. $5 B_{3}$ ), characterized by a $k$ of 9.09 and a $V_{1 / 2}(-56.93 \mathrm{mV})$ that was more negative than that of $I_{\mathrm{Na}}$ (compare Fig. $\left.1 A_{3}, B_{2}\right)$. To compare $I_{\mathrm{NaP}}$ activation in different conditions (see below) we also fitted the data of each neuron with a Boltzmann curve. From this analysis we obtained a $V_{1 / 2}$ of $-53.87 \pm 3.05 \mathrm{mV}$ and a $k=8.57 \pm 1.89$ $(n=4)$ (Table 1).

\section{Properties and occurrence of $I_{\mathrm{NaP}}$}

Additional properties of $I_{\mathrm{NaP}}$ were investigated in adult rat dLGN slices because of the greater amplitude of $I_{\mathrm{NaP}}$ in this preparation (Fig. 6). The effect of the rate of voltage change on the degree of $I_{\mathrm{NaP}}$ activation was investigated by varying the rate of rise of voltage ramps, and the amplitude of the pure $I_{\mathrm{NaP}}$ was then measured after TTX and leak subtraction. We also studied the effect of ramp rates in the physiological range from 0.1 to 0.5 $\mathrm{mV} / \mathrm{msec}$ (Fig. $6 A_{2}$ ). A rate of $0.1 \mathrm{mV} / \mathrm{msec}$ was sufficient to elicit $I_{\mathrm{NaP}}$, and the amplitude of $I_{\mathrm{NaP}}$ evoked by a rate of $0.5 \mathrm{mV} / \mathrm{msec}$ was double the one that was evoked at the lowest rate. Note that in this preparation, the fastest rates of rise were often sufficient to activate $I_{\mathrm{Na}}$ as well (Fig. $6 A_{1}$ ).

The possible inactivating effect of the holding potential or previous cellular activity was also investigated. For this analysis, $I_{\mathrm{NaP}}$ was elicited with a voltage ramp from -100 to $50 \mathrm{mV}$ while a conditioning potential was inserted between successive ramps to determine its effect on the amount of $I_{\mathrm{NaP}}$ evoked during the ramp (Fig. $6 B_{1}$ ). The magnitude of $I_{\mathrm{NaP}}$ was dependent on the conditioning potential during the inter-ramp interval, with less current being evoked after positive steps were increased. Thus, for example, only $60 \%$ of the maximal $I_{\mathrm{NaP}}$ could be elicited after a conditioning potential to $-50 \mathrm{mV}$ (Fig. $6 B_{2}$ ). 

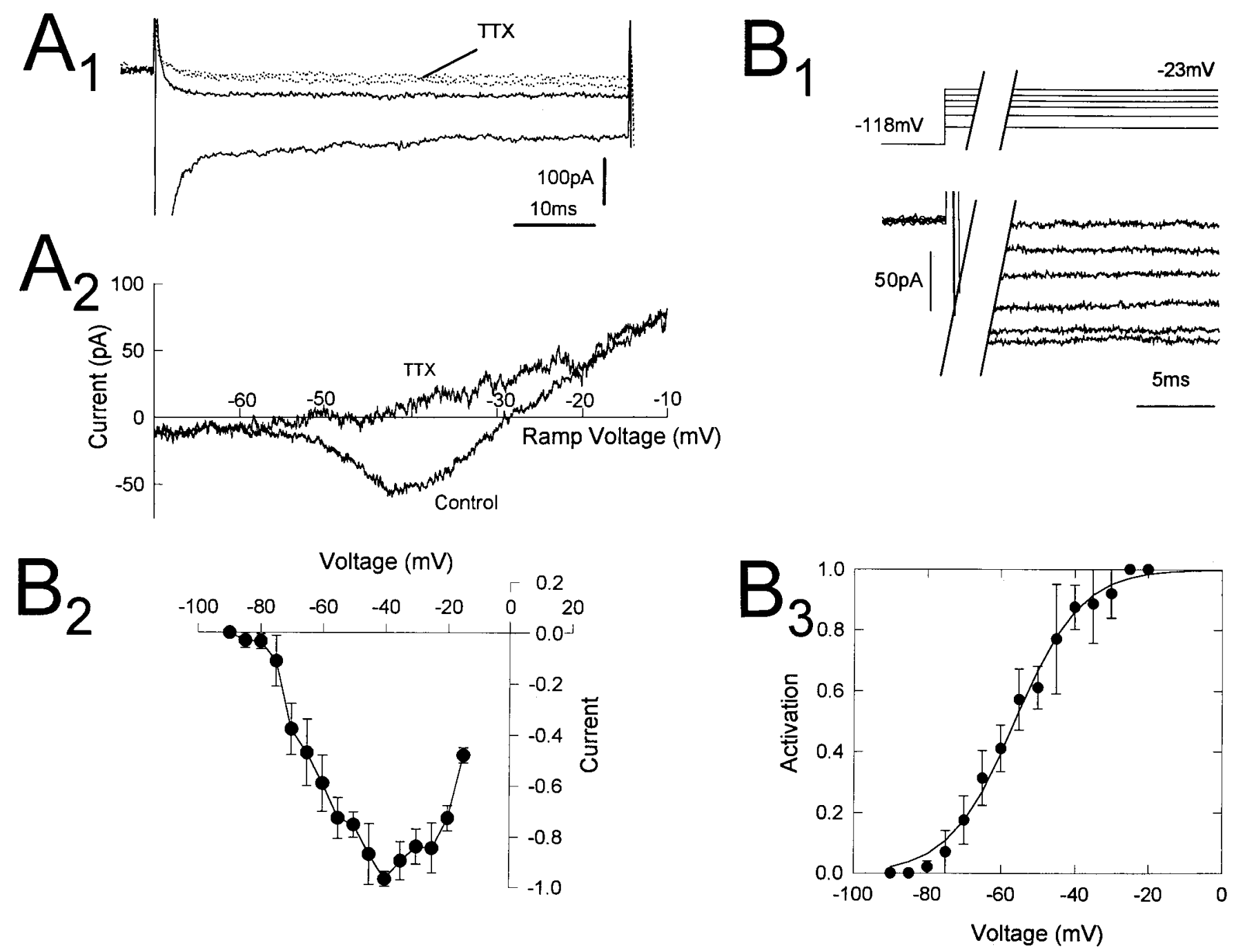

Figure 5. TTX-sensitive $I_{\mathrm{NaP}}$ in dLGN TC neurons. $A_{1}$, Two long voltage steps to -63 and $-38 \mathrm{mV}$ (from a holding potential of $-108 \mathrm{mV}$ ) elicit sustained inward currents $\left(I_{\mathrm{NaP}}\right)$ (solid traces). Dotted traces show that after addition of $1 \mu \mathrm{M}$ TTX to the perfusion medium, both $I_{\mathrm{Na}}$ and $I_{\mathrm{NaP}}$ are blocked. $A_{2}$, A sustained $\mathrm{Na}^{+}$current $\left(I_{\mathrm{NaP}}\right)$ could be elicited with a ramp voltage protocol. The traces show the effect of $1 \mu \mathrm{M}$ TTX on the inward current elicited by a voltage ramp of $0.2 \mathrm{mV} / \mathrm{msec}$ from $-118 \mathrm{mV}$. $B_{1}$, The activation of $I_{\mathrm{NaP}}$ was investigated using long step depolarizations. Traces show the current remaining up to $70 \mathrm{msec}$ after step depolarizations to $-88,-68,-53,-43,-33$, and $-23 \mathrm{mV}$. The saturating $I_{\mathrm{Na}}$ has been omitted for clarity (the break in the record equals $40 \mathrm{msec}$ ). $B_{2}$, Current-voltage relation for $I_{\mathrm{NaP}}$ derived from voltage protocols as in $B_{1}$. The amplitude of the current was measured at $60 \mathrm{msec}$ into the voltage step when the transient component had relaxed $(n=4)$. $B_{3}$, Activation curve for $I_{\mathrm{NaP}}$, derived from the same cells as in $B_{2}$. Points $(n=4)$ are fitted with a Boltzmann curve. All experiments were conducted in dissociated neonate rat neurons at room temperature.

To investigate possible subcellular, developmental, and species differences, the peak amplitude of $I_{\mathrm{NaP}}$ elicited during a 0.2 $\mathrm{mV} / \mathrm{msec}$ voltage ramp from -100 to $50 \mathrm{mV}$ was compared in different preparations, all perfused with $130 \mathrm{~mm}$ extracellular $\mathrm{Na}^{+}$except for neonate cat $(30 \mathrm{~mm})$ : neonate rat dissociated neurons, $52.27 \pm 10.9 \mathrm{pA}$ (or $4.7 \pm 0.5 \mathrm{pA} / \mathrm{pF})(n=11)$; neonate rat in slices, $86.22 \pm 8.6 \mathrm{pA}(n=18)$; adult rat in slices, $155.75 \pm$ $34.7 \mathrm{pA}(n=4)$; and neonate cat dissociated neurons, $92.8 \pm$ $28.16 \mathrm{pA}$ (or $4.6 \pm 1.3 \mathrm{pA} / \mathrm{pF})(n=5)$. The difference in $I_{\mathrm{NaP}}$ amplitude between dissociated neonate rat neurons and neurons in neonate rat slices was significant $(p<0.05)$, indicating the presence of this current in TC neuron dendrites. $I_{\mathrm{NaP}}$ amplitude in adult rat was significantly greater than $I_{\mathrm{NaP}}$ in dissociated neonate rat neurons $(p<0.001)$ and in neonate slice $(p<0.01)$. The difference in $I_{\mathrm{NaP}}$ between neonate rat and cat dissociated neurons was not statistically significant, even when peak current densities were compared $(p=0.89)$, but note that in dissociated neonate rat neurons recorded under similar conditions (i.e., in $30 \mathrm{~mm}$ extracellular $\mathrm{Na}^{+}$) $I_{\mathrm{NaP}}$ was almost immeasurable (i.e., $<5 \mathrm{pA}$ ).

\section{Mechanism of $I_{\mathrm{NaP}}$ manifestation}

To test the hypothesis that $I_{\mathrm{NaP}}$ could be produced by a proportion of the $\mathrm{Na}^{+}$channel population that was noninactivating, we performed experiments (in dissociated rat neurons and $20 \mathrm{~mm}$ $\left[\mathrm{Na}^{+}\right]_{\mathrm{o}}$ ) in which $1 \mathrm{mg} / \mathrm{ml}$ papain was included in the patchrecording pipette to cause removal of the inactivation gate (Cota and Armstrong, 1992; Brown et al., 1994). Because papain removed inactivation 15-20 min after commencement of whole-cell recording, it was possible to obtain control data on $I_{\mathrm{Na}}$ and then compare the current evoked after removal of inactivation. In the low extracellular $\mathrm{Na}^{+}$solution used $(20 \mathrm{mM}), I_{\mathrm{NaP}}$ was practically immeasurable, but after 20 min of papain treatment a $0.2 \mathrm{mV} /$ msec ramp protocol from -100 to $50 \mathrm{mV}$ elicited a large inward current $\left(I_{\text {papain }}\right)$ that peaked between -40 and $-30 \mathrm{mV}$ (Fig. $7 A$ ), 

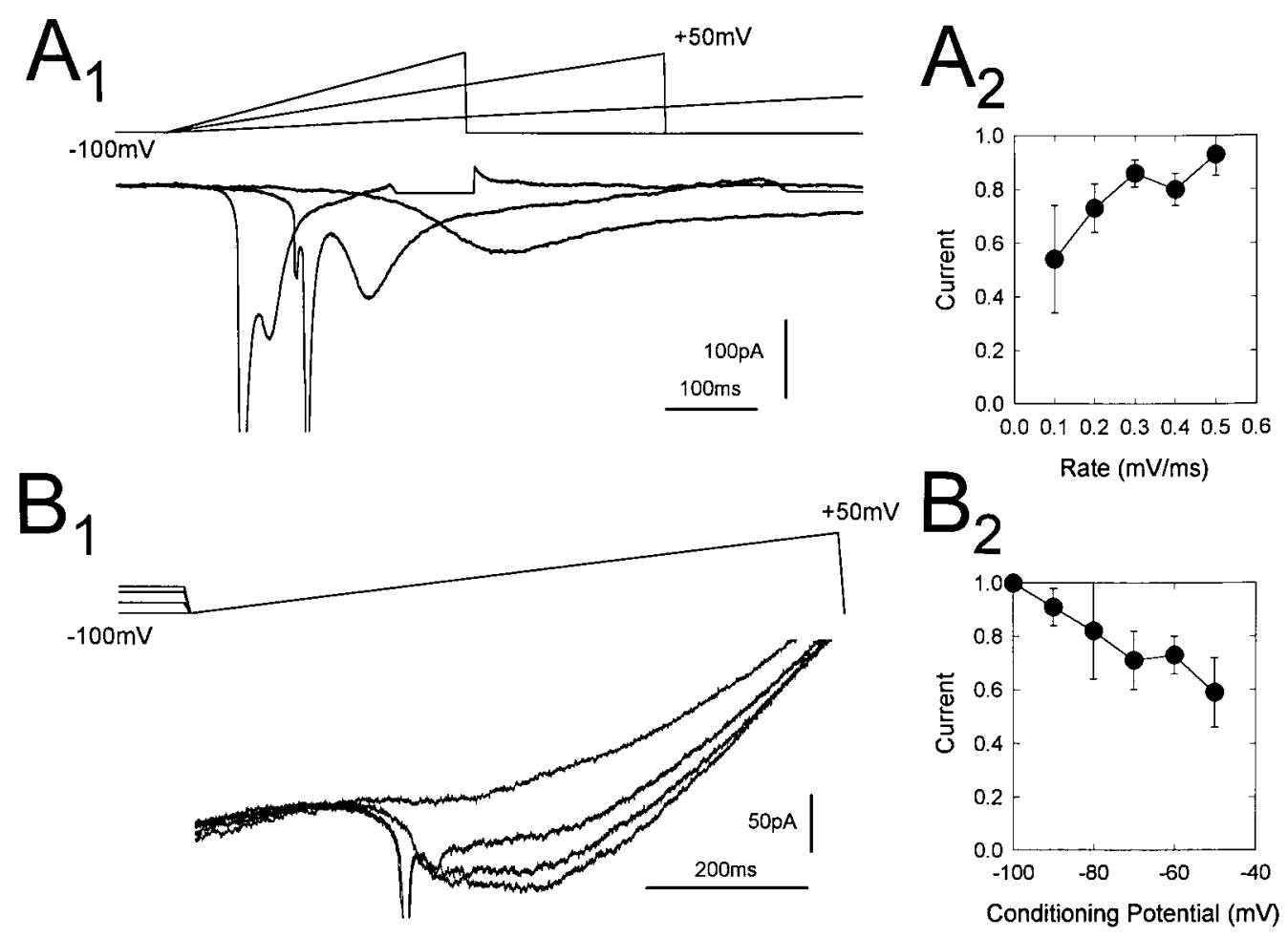

Rate $(\mathrm{mV} / \mathrm{ms})$
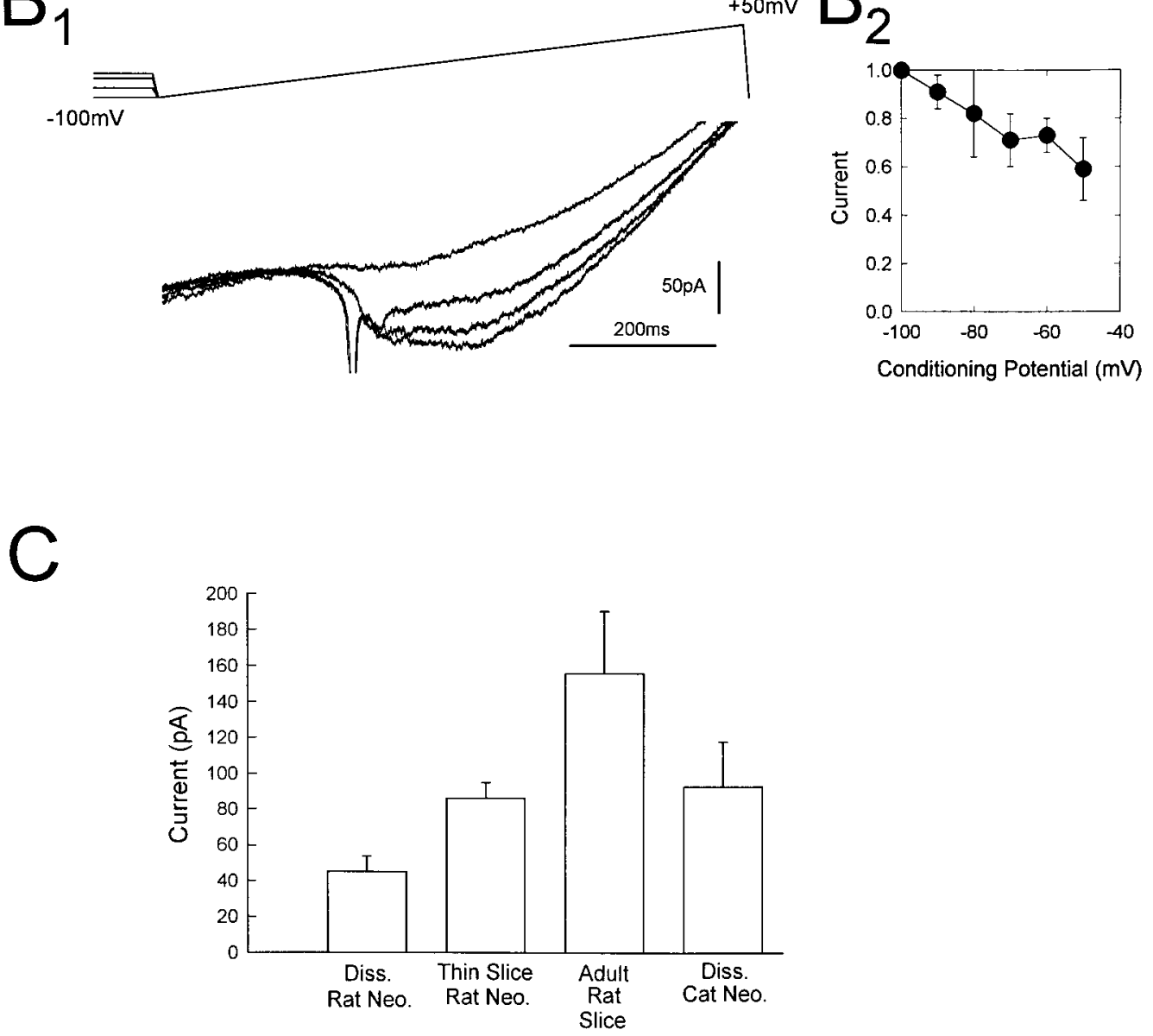

Figure 6. Steady-state properties of $I_{\mathrm{NaP}} A_{1}$, TTX-subtracted inward currents elicited by voltage ramps of $0.5,0.3$, and $0.1 \mathrm{mV} / \mathrm{msec}$ from a holding potential of $-100 \mathrm{mV}$ in an adult rat dLGN TC neuron. Note that ramps of higher rate cause transient spike as well as activation of sustained current. $A_{2}$, Amplitude of elicited $I_{\mathrm{NaP}}$ is dependent on the rate of voltage change. Plot of normalized $I_{\mathrm{NaP}}$ against ramp rise rate $(n=4)$. $B_{1}$, Amount of $I_{\mathrm{NaP}}$ depends on the holding potential. Traces show currents elicited during the ramp preceded either by 3 -sec-long voltage steps to $-80,-60$, and $-50 \mathrm{mV}$, or by no step. $B_{2}$, Plot of normalized $I_{\mathrm{NaP}}$ elicited with a ramp rate of $0.2 \mathrm{mV} / \mathrm{msec}$ against inter-ramp holding potential $(n=4)$. Experiments in $A$ and $B$ were conducted in slices from adult rats at $35^{\circ} \mathrm{C}$. C. Amplitude of $I_{\mathrm{NaP}}$ in different species and preparations; bar graph of $I_{\mathrm{NaP}}$ amplitude in dissociated neonate rat TC neurons $(n=11)$, neonate $(n=18)$ and adult $(n=4)$ rat TC neurons in slice, and dissociated neonate cat TC neurons $(n=5)$. Currents were measured in $130 \mathrm{~mm}$ extracellular $\mathrm{Na}^{+}$concentration for all groups, apart from cat neurons, in which the extracellular $\mathrm{Na}^{+}$was $30 \mathrm{~mm}$ (see Results for statistical significances). All data were obtained at room temperature except those in adult rat slices $\left(35^{\circ} \mathrm{C}\right)$.

similar to the ramp-evoked $I_{\mathrm{NaP}}$ in neurons that were recorded with papain-free electrodes.

Voltage step protocols were then used to obtain a more quantitative analysis of the properties of $I_{\text {papain }}$. We observed that papain treatment transformed transient $I_{\mathrm{Na}}$ currents elicited during step depolarizations to noninactivating currents (Fig. $7 B$ ) that activated at more hyperpolarized potentials (around $-70 \mathrm{mV}$ ) and peaked at $-40 \mathrm{mV}$ (Fig. $\left.7 C_{1}, C_{2}\right)$. In addition, there was no significant difference in the $V_{1 / 2}$ value between $I_{\mathrm{NaP}}$ (filled circles in Fig. $\left.7 C_{2}\right)$ and $I_{\text {papain }}(-56.92 \pm 0.96 \mathrm{mV} ; n=3$ ) (open circles in Fig. $\left.7 C_{2}\right)(p=0.86)$ or their $k$ value $\left(I_{\text {papain }}, k=6.31 \pm 0.56\right.$ $\mathrm{mV} ; n=3)(p=0.28)$ (Table 1).

To test the hypothesis that $I_{\mathrm{NaP}}$ was a manifestation of the window component of $I_{\mathrm{Na}}$, we compared $I_{\mathrm{NaP}}$ with the theoretical 


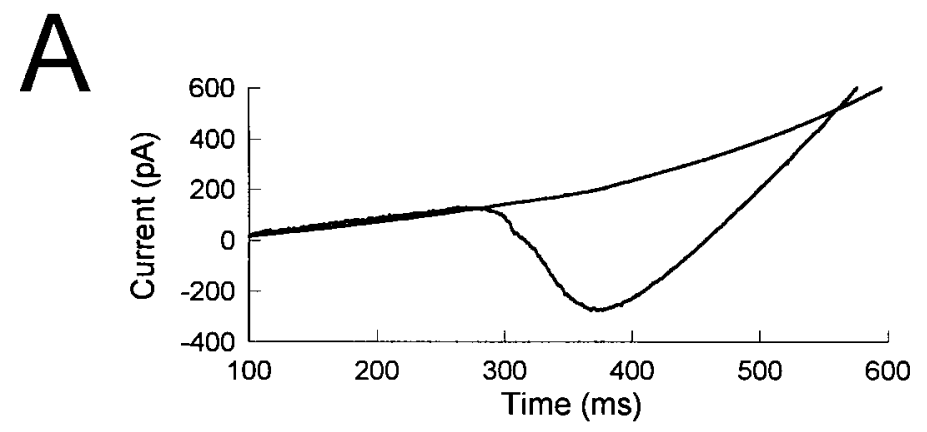

Figure 7. Removal of inactivation induces a current with the properties of $I_{\mathrm{NaP}} . A$, The top traces display currents activated with a ramp protocol immediately after breakthrough, and 20 min later, when an internal solution containing $1 \mathrm{mg} / \mathrm{ml}$ papain was used. The bottom trace displays the current induced by the action of papain and was derived by subtracting the current recorded at $t=0 \mathrm{~min}$ from the current at $t=20 \mathrm{~min}$. $B$, Papain causes the removal of fast inactivation of $I_{\mathrm{Na}}$ in TC neurons. Traces show currents elicited by step depolarizations during control conditions soon after breakthrough, and 20 min after recording with papain containing internal solution. $C_{1}$, Current-voltage relation of the noninactivating current in papain-treated cells ( filled circles; $n=3$ ) is superimposed on the current-voltage relation of $I_{\mathrm{NaP}}$ taken from Figure $5 B_{2}$ (open circles) for comparison. The dotted line at the base of the plot shows the theoretical $I_{\mathrm{Na}}$ window current calculated as described in the text. $C_{2}$, Activation curve for current in papaintreated cells (filled circles; $n=3$ ) is superimposed on the activation curve for $I_{\mathrm{NaP}}$ taken from Figure $5 B_{3}$ (open circles) for comparison. All experiments were conducted in dissociated neonate rat neurons at room Ramp Voltage $(\mathrm{mV})$

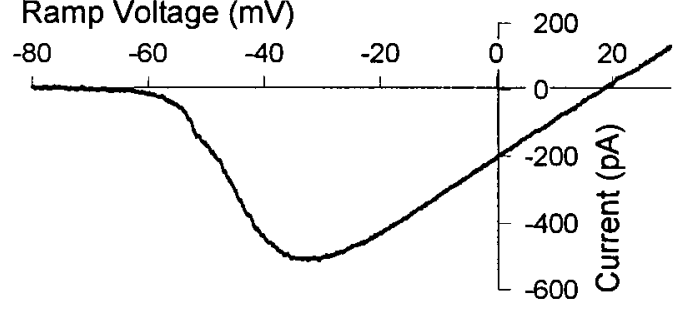

B

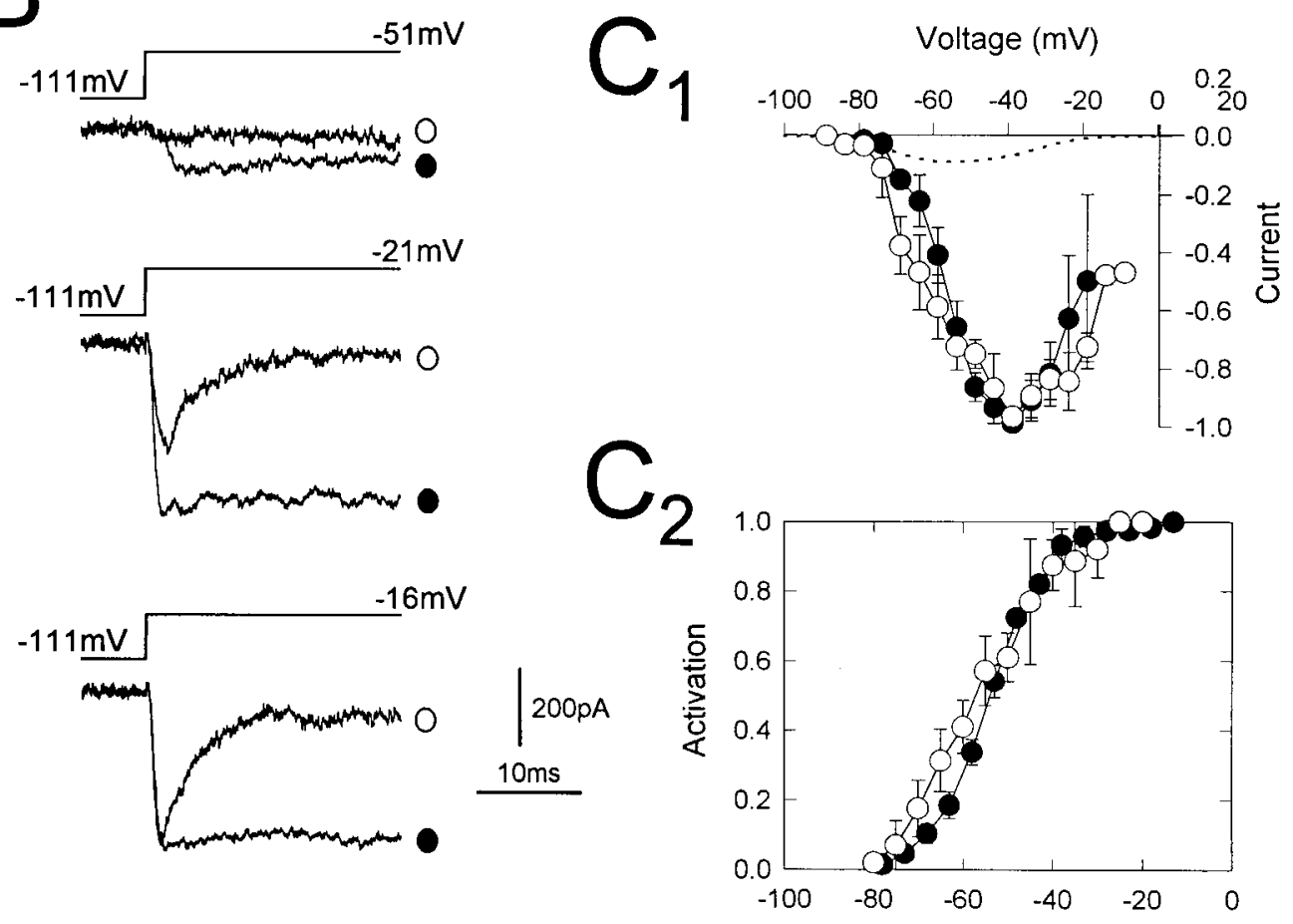

$I_{\mathrm{Na}}$ window current. The measured $I_{\mathrm{NaP}}(52.27 \mathrm{pA}$, see above $)$ peaked at $-39 \mathrm{mV}$, and its amplitude was $2.5 \%$ of the peak $I_{\mathrm{Na}}$ $(2106 \pm 208 \mathrm{pA} ; n=9)$. The theoretical window component was calculated from the product of the Boltzmann fits for the steadystate activation and inactivation curves recorded with papain-free electrodes (compare Fig. $1, A_{3}$ and $B_{2}$ ), and the mean conductance of $I_{\mathrm{Na}}$ from neurons recorded in $130 \mathrm{~mm}$ extracellular $\mathrm{Na}^{+}$. This predicted current (dotted line in Fig. $7 C_{1}$ ) peaked at $-55 \mathrm{mV}$ and had an amplitude of $4.7 \mathrm{pA}$. The difference in voltage dependence and amplitude, therefore, suggests that $I_{\mathrm{NaP}}$ is not a manifestation of the window current of $I_{\mathrm{Na}}$. We also calculated window $I_{\mathrm{Na}}$ by using the results of a detailed voltage-clamp analysis method (Tóth and Crunelli, 1995) in which the steadystate activation curve is obtained without "contamination" by activation or inactivation kinetics. Even in this case, however, the amplitude of the calculated window $I_{\mathrm{Na}}$ was $<1 \mathrm{pA}$, and thus much smaller than the measured $I_{\mathrm{NaP}}$. Finally, evidence that $I_{\mathrm{NaP}}$ was not a manifestation of window $I_{\mathrm{Na}}$ was obtained by the experiments in which positive holding currents were seen to have an inactivating effect on ramp-elicited $I_{\mathrm{NaP}}$ (Fig. $6 B_{1}$ ), because window currents are not expected to be affected by such potentials (Hirano et al., 1992).

\section{Role of $\boldsymbol{I}_{\mathrm{NaP}}$ in tonic and burst firing of TC neurons}

After the existence and properties of $I_{\mathrm{NaP}}$ in TC neurons were established, we investigated the possible physiological role of this current using current-clamp recordings from adult rat dLGN slices (Fig. 8). The membrane properties of these neurons were similar to those described previously for TC neurons in identical recording conditions (resting membrane potential: $-62 \pm 2 \mathrm{mV}$; 
apparent steady-state input resistance: $191 \pm 24 \mathrm{M} \Omega ; n=10$ ). The effect on tonic firing was investigated by recording from TC neurons held at membrane potentials more than or equal to -60 $\mathrm{mV}$, from where low threshold $\mathrm{Ca}^{2+}$ potentials could not be evoked by positive current steps (Fig. $8 A_{1}$ ). Positive current steps were applied in control conditions and in the presence of $1 \mu \mathrm{M}$ TTX to investigate the contribution of $\mathrm{Na}^{+}$currents in this region of the voltage-current relationship. TTX produced a block of the action potentials and also a reduction in the extent of the depolarization elicited by the positive current steps (Fig. $8 A_{2}$ ). The greatest contribution of the TTX-sensitive component $(3.3 \pm 0.5 \mathrm{mV}$; range, $2.5-4.0 \mathrm{mV} ; n=3)$ was at potentials closest to firing threshold (Jahnsen and Llinás, 1984a,b).

To investigate the possibility that $I_{\mathrm{NaP}}$ might also have an involvement in the burst firing of TC neurons, neurons were held at $-70 \mathrm{mV}$, and positive current steps were then delivered to activate the low-threshold $\mathrm{Ca}^{2+}$ potential and associated burstfiring response. These experiments were performed in the presence of ZD $7288(200 \mu \mathrm{M})$, a specific blocker of the hyperpolarization-activated inward current $I_{\mathrm{h}}$ (Harris and Constanti, 1995; Williams et al., 1997), to eliminate the effect of changes in this current on the measured parameters (Pape, 1994; Hughes et al., 1996). For the neuron shown in Figure $8 B$, a 40 pA current step in control conditions elicited a robust low-threshold $\mathrm{Ca}^{2+}$ potential crowned by a burst of action potentials. After 1 $\mu \mathrm{M}$ TTX application, however, the same current step only produced a much smaller and delayed low-threshold $\mathrm{Ca}^{2+}$ potential (Fig. $8 B_{1}$, left). With a current step of $50 \mathrm{pA}$ the low-threshold $\mathrm{Ca}^{2+}$ potential recorded in the presence of TTX was also delayed compared with that in control conditions (Fig. $8 B_{1}$, middle), but with a current step of $80 \mathrm{pA}$ the low-threshold $\mathrm{Ca}^{2+}$ potential profiles in control and TTX conditions were almost indistinguishable (Fig. $8 B_{1}$, right). The addition of TTX, therefore, had two effects: (1) a large decrease $(67 \pm 6 \% ; n=4)$ in the amplitude of the low-threshold $\mathrm{Ca}^{2+}$ potential (measured at the lowest input current required to evoke a full-blown $\mathrm{Ca}^{2+}$ potential in control conditions) and (2) a significant increase in the latency of the low-threshold $\mathrm{Ca}^{2+}$ potential, measured from the onset of the current step (control: $83 \pm 19$ msec; TTX: $115 \pm 18$ msec; $n=4$; $p<0.05$; paired $t$ test). Because these changes in burst-firing properties produced by TTX were observed within a narrow range of membrane potentials $(-75$ to $-65 \mathrm{mV})$ and with relatively small positive current steps (20-200 pA), extreme care was taken to ensure that cell deterioration and shifts in membrane potential did not occur during the course of these experiments. Results in control and experimental conditions were carefully compared, and any neuron that displayed deterioration in the quality of the recording was excluded from the analysis. In addition, low-threshold $\mathrm{Ca}^{2+}$ potentials were evoked in the presence of TTX not only from the same holding potential as in the control conditions (i.e., $-70 \mathrm{mV}$ ) (Fig. $\left.8 B_{1}\right)$ but also at potentials slightly more negative and positive (Fig. $8 B_{2}, B_{3}$ ). Thus, positive current steps delivered from $-68 \mathrm{mV}$ (Fig. $88 B_{2}$ ) elicited low-threshold $\mathrm{Ca}^{2+}$ potentials that were markedly reduced in amplitude and delayed compared with the control potentials at $-70 \mathrm{mV}$, suggesting that the effect observed at $-70 \mathrm{mV}$ in the presence of TTX was not caused by a negative shift in membrane potential during the experiment. Similarly, holding the neuron at $-72 \mathrm{mV}$ (Fig. $8 B_{3}$ ), from where a larger underlying $I_{\mathrm{T}} \mathrm{Ca}^{2+}$ current is generated, still elicited low-threshold $\mathrm{Ca}^{2+}$ potentials that were delayed and displayed profiles that were not superimposable on the control potentials.

\section{DISCUSSION}

The main conclusions of this study are that (1) $I_{\mathrm{NaP}}$ exists in TC neurons; (2) a single $\mathrm{Na}^{+}$current type appears to underlie both $I_{\mathrm{Na}}$ and $I_{\mathrm{NaP}}$, with the latter being formed by a noninactivating component of $\mathrm{I}_{\mathrm{Na}}$; and (3) $I_{\mathrm{NaP}}$ contributes to both tonic and burst firing of TC neurons.

\section{Steady-state and kinetic properties of $I_{\mathrm{Na}}$}

The properties of $I_{\mathrm{Na}}$ in TC neurons are in general agreement with measurements of the action potential generating $I_{\mathrm{Na}}$ in other CNS preparations. In particular, for $I_{\mathrm{Na}}$ activation our values of $V_{1 / 2}$ and $k$ fall within the range of those reported by other investigators (from -39 to $-28 \mathrm{mV}$ and from 4.2 to 7.1 , respectively), and similarly for the inactivation (from -90 to $-60 \mathrm{mV}$ and from 4.4 to 10.2, respectively) (Huguenard et al., 1988; Sah et al., 1988; Fan et al., 1994; Magee and Johnston, 1995; Safronov and Vogel, 1995). Single channel recordings have reported $I_{\mathrm{Na}}$ decays to be best fitted with a single exponential in motoneuron soma (Safronov and Vogel, 1995) or two exponentials in hippocampal neuron dendrites (Magee and Johnston, 1995). In TC neurons $I_{\mathrm{Na}}$ decays could be well fitted with a single exponential, which suggests therefore a single type of $\mathrm{Na}^{+}$channel population.

From the steady-state inactivation data it seems that at a typical resting membrane potential of $-60 \mathrm{mV}$ only $\sim 20 \%$ of the $\mathrm{Na}^{+}$ channel population is available for activation in TC neurons. A hyperpolarizing episode would therefore be expected to remove inactivation and increase the available $\mathrm{Na}^{+}$channel population, allowing for more robust action potential firing on subsequent depolarization. This feature could explain why the frequency of the burst firing evoked by low-threshold $\mathrm{Ca}^{2+}$ potentials in rat TC neurons of the dLGN and other thalamic sensory nuclei reaches a maximum of $\sim 450 \mathrm{~Hz}$, whereas in tonic firing the maximum frequency does not exceed $200 \mathrm{~Hz}$ (Huguenard and Prince, 1994; Jahnsen and Llinás, 1984a; Williams et al., 1996). Indeed, it would be interesting to investigate the onset and recovery from inactivation of $I_{\mathrm{Na}}$ in intralaminar thalamic nuclei in which burst firing frequencies of up to $1 \mathrm{kHz}$ have been observed (Steriade et al., 1993).

\section{Properties of inactivation}

From the experiments on the onset of inactivation at $-68 \mathrm{mV}$, it is evident that the amplitude of $I_{\mathrm{Na}}$ decreases to $\sim 50 \%$ of the initial value within $300 \mathrm{msec}$. This onset has a rapid and a slow component. In neocortical neurons a slow entry into an inactivated state has been shown to have a marked effect on output firing patterns (Fleidervish et al., 1996), whereas the contribution of this process to TC neuron firing remains to be determined. Recovery from inactivation at holding potentials more negative than $-70 \mathrm{mV}$ follow single exponential profiles, whereas at more positive (i.e., physiological) potentials an additional slower recovery from inactivation is also seen. The inability to fit recoveries at these potentials with a single exponential indicates that the relative values of the $\tau$ of activation and the $\tau$ of inactivation converge. At more negative potentials, single exponential fits show that activation is much faster than inactivation (Tóth and Crunelli, 1996).

The decrease in firing frequency observed in TC neurons during long periods of depolarization more than $-40 \mathrm{mV}$ (Williams et al., 1996; Turner et al., 1997) will depend on the interplay between the onset of, and the recovery from, inactivation as well as on the contribution of $\mathrm{K}^{+}$and high-threshold $\mathrm{Ca}^{2+}$ currents. 

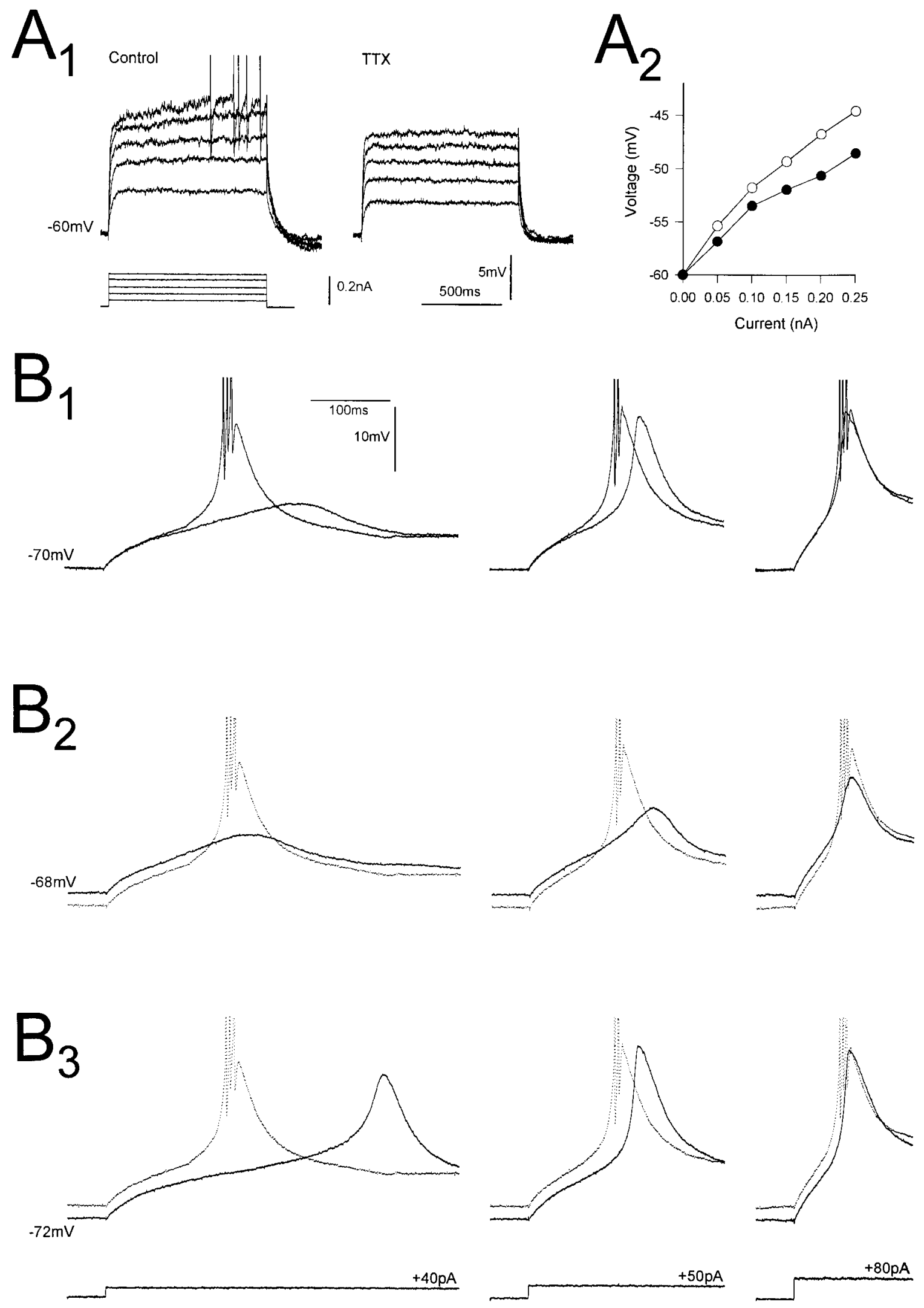

Figure 8. Role of $I_{\mathrm{NaP}}$ in tonic and burst firing of TC neurons. $A_{1}$, Voltage deflections produced by positive current steps from $-60 \mathrm{mV}$ in control conditions and in the presence of $1 \mu \mathrm{M}$ TTX. $A_{2}$, Steady-state voltage-current relation for the neuron in $A_{1}$ measured 20 msec before the end of the current step (control: open circles; TTX: filled circles). $B_{1}$, Burst firing produced by current steps of 40,50, and $80 \mathrm{pA}$ from a membrane potential of $-70 \mathrm{mV}$ in control conditions (traces with action potentials) and after the addition of $1 \mu \mathrm{M}$ TTX. Note the smaller and delayed low-threshold $\mathrm{Ca}^{2+}$ potential in the presence of TTX. $B_{2}$ and $B_{3}$ show responses in TTX (continuous traces) at membrane potentials $-68 \mathrm{mV}$ and $-72 \mathrm{mV}$, respectively, (Figure legend continues.) 
The dynamics of this complex interplay in determining the pattern of TC neuron output under different levels of excitability (Turner et al., 1997) could now be carefully examined using both experimental and simulation studies.

\section{Mechanism of $I_{\mathrm{NaP}}$ manifestation}

The three general hypotheses put forward to explain the occurrence of $I_{\mathrm{NaP}}$ have been elegantly summarized in a recent review (Crill, 1996). (1) $I_{\mathrm{NaP}}$ is a manifestation of the window component of $I_{\mathrm{Na}}$; (2) $I_{\mathrm{NaP}}$ is a distinct channel type that displays kinetic properties different from $I_{\mathrm{Na}}$; and (3) $I_{\mathrm{NaP}}$ is produced by either a loss, or modulation, of inactivation of the same channels that underlie $I_{\mathrm{Na}}$.

The voltage dependence of $I_{\mathrm{NaP}}$ and window $I_{\mathrm{Na}}$ in TC neurons was different, because the maximal amplitude was observed at $-40 \mathrm{mV}$ and $-55 \mathrm{mV}$, respectively. Another difference was that the maximal amplitude of $I_{\mathrm{NaP}}$ was $\sim 2 \%$ of the whole-cell current, whereas the calculated peak $I_{\mathrm{Na}}$ window current would account for only $0.2 \%$ of the whole-cell current. In addition, changes in the inter-ramp holding potential were seen to affect markedly the amplitude of $I_{\mathrm{NaP}}$ elicited during a subsequent voltage ramp, whereas window current amplitude should be independent of the holding potential (Hirano et al., 1992). We therefore conclude that $I_{\mathrm{NaP}}$ in TC neurons cannot be explained as a manifestation of the $I_{\mathrm{Na}}$ window current.

Because of the lack of availability of toxins specific for different subtypes of $\mathrm{Na}^{+}$channels, it is only possible to distinguish between channel types on the basis of kinetics or single channel conductance. There is a clear difference in the activation range of $I_{\mathrm{NaP}}$ and $I_{\mathrm{Na}}$ in TC neurons that has been found in almost all other cell types studied (French et al., 1990; Saint et al., 1992). This point, however, is insufficient to prove the involvement of a different channel type and could be attributed to the appearance of another "mode" of channel gating (Alzheimer et al., 1993) or to a subpopulation of $\mathrm{Na}^{+}$channels having "lost" their ability to inactivate. $I_{\mathrm{NaP}}$ could therefore arise from this population of channels, as predicted from the Hodgkin and Huxley model (Hodgkin and Huxley, 1952). The lack of inactivation has been suggested as a likely mechanism in neocortical pyramidal neurons (Brown et al., 1994).

The inactivation hypothesis was tested by including papain in the recording pipette. This caused a removal of inactivation of $I_{\mathrm{Na}}$, transforming the rapidly inactivating current into a sustained one. The greatly enlarged current seen during ramp protocols with papain-containing electrodes had a voltage dependence similar to the $I_{\mathrm{NaP}}$ evoked during similar voltage protocols in control conditions. Current-voltage relations of $I_{\text {papain }}$ constructed with voltage step protocols were also similar to $I_{\mathrm{NaP}}$ in untreated cells, displaying comparable voltages of maximal amplitude and similar voltage dependence. Activation curves constructed for $I_{\text {papain }}$ also had $V_{1 / 2}$ and $k$ values that were not different from those of $I_{\mathrm{NaP}}$ recorded with papain-free electrodes. Cell-attached recordings in other neuronal types have also failed to detect a distinct $\mathrm{Na}^{+}$ channel population underlying $I_{\mathrm{NaP}}$ (Alzheimer et al., 1993; Magee and Johnston, 1995; Safronov and Vogel, 1995), and it is clear that the only conclusive way of ruling out the involvement of a different $\mathrm{Na}^{+}$channel subtype would be to perform single channel recordings in TC neurons. In Purkinje neurons, a "resurgent $\mathrm{Na}^{+}$current" has recently been described that is thought to derive from $\mathrm{Na}^{+}$channels recovering from inactivation via an open state (Raman and Bean, 1997). The properties of such a current, however, cannot explain our findings that the greatest $I_{\mathrm{NaP}}$ contribution occurs below firing threshold in current-clamp experiments and that $I_{\mathrm{NaP}}$ is increased by the removal of inactivation by papain. In view of the striking similarity of $I_{\text {papain }}$ and $I_{\mathrm{NaP}}$, however, we suggest that the existence of a different channel type is not required to explain $I_{\mathrm{NaP}}$ in $\mathrm{TC}$ neurons and that at present the most parsimonious conclusion of our results is that the appearance of $I_{\mathrm{NaP}}$ is caused by the absence of inactivation in a subset of the $\mathrm{Na}^{+}$channel population underlying $I_{\mathrm{Na}}$. The fact that one channel type potentially underlies two very different electrophysiological roles is in itself very interesting, as is the possibility that the mechanism responsible for the loss of inactivation may be under cellular control, a suggestion supported by our experiments on the removal of inactivation by intracellular papain.

\section{Physiological role of $\boldsymbol{I}_{\mathrm{NaP}}$}

The TTX-sensitive $I_{\mathrm{NaP}}$ first activated at membrane potentials around $-70 \mathrm{mV}$, confirming the observation in other systems that this current activates at potentials more negative than those of $I_{\mathrm{Na}}$. Indeed, the $V_{1 / 2}$ of $I_{\mathrm{NaP}}$ in TC neurons is $\sim 20 \mathrm{mV}$ more negative than the $V_{1 / 2}$ of the $I_{\mathrm{Na}}$ measured in this study and similar to the one found in dorsal root ganglion cells and in hippocampal and neocortical neurons (French et al., 1990; Brown et al., 1994; Baker and Bostock, 1997). This relatively more negative activation of $I_{\mathrm{NaP}}$ suggests a number of putative physiological roles in $\mathrm{TC}$ neurons over a wide range of membrane potentials.

A maximum amplitude of $\sim 150 \mathrm{pA}$ in adult rat TC neurons suggests that for a neuron with an apparent input resistance of $100 \mathrm{M} \Omega$, activation of $I_{\mathrm{NaP}}$ could cause a depolarization of 10 $\mathrm{mV}$. The current-voltage relation for $I_{\mathrm{NaP}}$ shows that between 60 and $80 \%$ of this current will be activated in the membrane potential range between $-60 \mathrm{mV}$ and action potential firing threshold, predicting therefore that $I_{\mathrm{NaP}}$ would have its greatest influence on membrane potential in this voltage range. Indeed, the contribution of a TTX-sensitive, $I_{\mathrm{NaP}}$-mediated component to the voltage response of TC neurons to positive current steps was confirmed to be maximal in the voltage range immediately below firing threshold, but its amplitude was much less than predicted. This could be attributable to the large effect of $\mathrm{K}^{+}$-dependent rectification in this voltage region or to the reduction of the $I_{\mathrm{NaP}}$ elicited during prolonged depolarization at potentials more than or equal to $-60 \mathrm{mV}$ (as seen in the conditioning potential experiments). Overall, previous studies in guinea pig and bird TC neurons have shown a larger amplitude (up to $10 \mathrm{mV}$ ) of a similar TTX-sensitive component, a result that can be explained by the presence of a higher extracellular $\mathrm{K}^{+}$concentration and the consequent smaller contribution of $\mathrm{K}^{+}$-dependent outward current in the depolarizing responses observed in these studies (Jahnsen and Llinás, 1984b; Ströhmann et al., 1994; Tennigkeit et

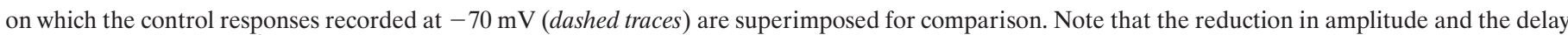

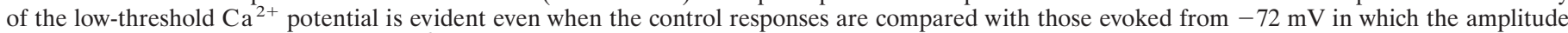

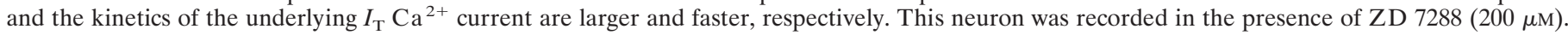
The amplitude of the action potentials has been truncated for clarity, and the experiments were conducted in slices from adult rats at $35^{\circ} \mathrm{C}$. 
al., 1996). In contrast to the prominent role of $I_{\mathrm{NaP}}$ in the high-frequency oscillations of cortical neurons, the presence of this current is not essential for the expression of these oscillations in TC neurons (Pedroarena and Llinás, 1997).

The activation of $I_{\mathrm{NaP}}$ at around $-70 \mathrm{mV}$ would also suggest a possible physiological role at this voltage level. If $I_{\mathrm{NaP}}$ activation was sufficiently rapid, then a synergistic relationship of $I_{\mathrm{NaP}}$ and $I_{\mathrm{T}}$ in the generation of low-threshold $\mathrm{Ca}^{2+}$ potentials and associated burst firing would be expected. Despite the fact that $I_{\mathrm{NaP}}$ is predicted to be small at potentials close to $-70 \mathrm{mV}$, the effect of removing this current on the amplitude and latency of a lowthreshold $\mathrm{Ca}^{2+}$ potential was remarkable. Indeed, although the action of $I_{\mathrm{NaP}}$ on the low-threshold $\mathrm{Ca}^{2+}$ potential was confined to a small range of membrane potentials, it undoubtedly affected both the efficacy of burst firing and the delay between triggering and firing. To the best of our knowledge this is the first example of $I_{\mathrm{NaP}}$ fulfilling an important amplification role in this voltage range, and it suggests a potentially pivotal involvement of this current in the burst-generating mechanism of TC neurons and a possible modulatory target. Moreover, in view of the presence of dendritic T-type $\mathrm{Ca}^{2+}$ channels in TC neurons (Zhou et al., 1997) and their involvement in information processing (Guido and Weyland, 1995), our findings of a contribution of $I_{\mathrm{NaP}}$ to burst firing and its somatodendritic location suggest that this current plays a major role in the integration of sensory and cortical inputs over a relatively wide range of membrane potentials.

\section{REFERENCES}

Alzheimer C (1994) A novel voltage-dependent cation current in rat neocortical neurones. J Physiol (Lond) 479:199-205.

Alzheimer C, Schwindt PC, Crill WE (1993) Modal gating of $\mathrm{Na}^{+}$ channels as a mechanism of persistent $\mathrm{Na}^{+}$current in pyramidal neurons from rat and cat sensorimotor cortex. J Neurosci 13:660-673.

Antal K, Emri Z, Tóth TI, Crunelli V (1996) Model of a thalamocortical neurone with dendritic voltage-gated ion channels. NeuroReport 7:2655-2658.

Baker MD, Bostock H (1997) Low-threshold, persistent sodium current in rat large dorsal root ganglion neurones in culture. J Neurophysiol 77:1503-1513.

Barry PH, Lynch JW (1991) Liquid junction potentials and small cell effects in patch-clamp analysis. J Membr Biol 121:101-117.

Barth DS, MacDonald KD (1996) Thalamic modulation of highfrequency oscillating potentials in auditory cortex. Nature 383:78-81.

Belluzzi O, Sacchi O (1991) A five-conductance model of the action potential in rat sympathetic neuron. Prog Biophys Mol Biol 55:1-30.

Brown AM, Schwindt PC, Crill WE (1994) Different voltage dependence of transient and persistent $\mathrm{Na}^{+}$currents is compatible with modal-gating hypothesis for sodium channels. J Neurophysiol 71:2562-2565.

Budde T, Mager R, Pape H-C (1992) Different types of potassium outward current in relay neurons acutely isolated from the rat lateral geniculate nucleus. Eur J Neurosci 4:708-722.

Connors BW (1994) Intrinsic neuronal physiology and the functions, dysfunctions and development of neocortex. Prog Brain Res 102:195-203.

Cota G, Armstrong CM (1992) Analysis of sodium channel tail currents. Methods Enzymol 207:806-817.

Crill WE (1996) Persistent sodium current in mammalian central neurons. Annu Rev Physiol 58:349-362.

Crunelli V, Kelly JS, Leresche N, Pirchio M (1987) The ventral and dorsal lateral geniculate nucleus of the rat: intracellular recordings in vitro. J Physiol (Lond) 384:587-601.

Destexhe A, McCormick DA, Sejnowski TJ (1993) A model for 8-10 Hz spindling in interconnected thalamic relay and reticularis neurons. Biophys J 65:2473-2477.

Fan S, Stewart M, Wong RKS (1994) Differences in voltage-dependent sodium currents exhibited by superficial and deep layer neurons of guinea pig entorhinal cortex. J Neurophysiol 71:1986-1991.

Fleidervish IA, Gutnick MJ (1996) Kinetics of slow inactivation of per- sistent sodium current in layer $\mathrm{V}$ neurons of mouse neocortical slices. J Neurophysiol 76:2125-2130.

Fleidervish IA, Friedman A, Gutnick MJ (1996) Slow inactivation of $\mathrm{Na}^{+}$current and slow cumulative spike adaptation in mouse and guinea-pig neocortical neurones in slices. J Physiol (Lond) 493:83-97.

French CR, Sah P, Buckett KT, Gage PW (1990) A voltage-dependent persistent sodium current in mammalian hippocampal neurons. J Gen Physiol 95:1139-1157.

Guido W, Weyland T (1995) Burst responses in thalamic relay cells in the awake behaving cat. J Neurophysiol 74:1782-1786.

Harris NC, Constanti A (1995) Mechanism of block by ZD-7288 of the hyperpolarization-activated inward rectifying current in guinea-pig substantia-nigra neurons in vitro. J Neurophysiol 74:2366-2378.

Heinemann SH, Terlau H, Imoto K (1992) Molecular basis for pharmacological differences between brain and cardiac sodium channels. Pflügers Arch 422:90-92.

Hernandez-Cruz A, Pape H-C (1989) Identification of two calcium currents in acutely dissociated neurons from the rat lateral geniculate nucleus. J Neurophysiol 61:1270-1283.

Hirano Y, Moscucci A, January CT (1992) Direct measurements of L-type window current in heart cells. Circ Res 70:445-455.

Hodgkin AL, Huxley AF (1952) A quantitative description of membrane current and its application to conduction and excitation in nerve. J Physiol (Lond) 117:500-544.

Hughes SW, Tóth TI, Williams SR, Ceci A, Crunelli V (1996) Introducing computer-generated conductances into thalamocortical neurones. Soc Neurosci Abstr 22:631.19.

Huguenard JR, Prince DA (1991) Slow inactivation of a TEA-sensitive K current in acutely isolated rat thalamic relay neurons. J Neurophysiol 66:1316-1328.

Huguenard JR, Prince DA (1994) Intrathalamic rhythmicity studied in vitro: nominal T-current modulation causes robust antioscillatory effects. J Neurosci 14:5485-5502.

Huguenard JR, Hamill OP, Prince DA (1988) Developmental changes in $\mathrm{Na}^{+}$conductances in rat neocortical neurons: appearance of a slowly inactivating component. J Neurophysiol 59:778-795.

Jahnsen H, Llinás R (1984a) Electrophysiological properties of guineapig thalamic neurones: an in vitro study. J Physiol (Lond) 349:205-226.

Jahnsen H, Llinás R (1984b) Ionic basis for the electroresponsiveness and oscillatory properties of guinea-pig thalamic neurones in vitro. J Physiol (Lond) 349:227-247.

Jeanmonod D, Magnin M, Morel A (1996) Low-threshold calcium spike burst in the human thalamus: common physiopathology for sensory, motor and limbic positive symptoms. Brain 119:363-375.

Kay AR, Wong RKS (1986) Isolation of neurons suitable for patchclamping from adult mammalian central nervous systems. J Neurosci Methods 16:227-238.

Leresche N (1992) Synaptic currents in thalamo-cortical neurons of the rat lateral geniculate nucleus. Eur J Neurosci 4:595-602.

Lipowsky R, Gillessen T, Alzheimer C (1996) Dendritic $\mathrm{Na}^{+}$channels amplify EPSPs in hippocampal CA1 pyramidal cells. J Neurophysiol 76:2181-2191.

Llinás RR, Grace AA, Yarom Y (1991) In vitro neurons in mammalian cortical layer 4 exhibit intrinsic oscillatory activity in the $10-$ to $50-\mathrm{Hz}$ frequency range. Proc Natl Acad Sci USA 88:897-901.

Magee JC, Johnston D (1995) Characterization of single voltage-gated $\mathrm{Na}^{+}$and $\mathrm{Ca}^{2+}$ channels in apical dendrites of rat CA1 pyramidal neurons. J Physiol (Lond) 487:67-90.

Malafosse A, Genton P, Hirsch E, Marescaux C, Broglin D, Bernasconi R (1994) Idiopathic generalized epilepsies: clinical, experimental and genetic aspects. Paris: John Libbey.

McCormick DA, Bal T (1997) Sleep and arousal: thalamocortical mechanisms. Annu Rev Neurosci 20:185-215.

McCormick DA, Huguenard JR (1992) A model of the electrophysiological properties of thalamocortical relay neurons. J Neurophysiol 68:1384-1400.

Neher E (1992) Correction of liquid junction potentials in patch clamp experiments. Methods Enzymol 207:123-131.

Noda M, Ikeda T, Kayano T, Suzuki H, Takeshima H, Kuraski M, Takahashi H, Numa S (1986) Existence of distinct sodium channel messenger RNAs in rat brain. Nature 320:188-192.

Oh K-S, Lee C-J, Gibbs JW, Coulter DA (1995) Postnatal development of $\mathrm{GABA}_{\mathrm{A}}$ receptor function in somatosensory thalamus and cortex: whole-cell voltage-clamp recordings in acutely isolated rat neurons. J Neurosci 15:1341-1351. 
Pape H-C (1994) Specific bradycardic agents block the hyperpolarizationactivated cation current in central neurons. Neuroscience 59:363-373.

Parri HR, Leresche N, Crunelli V (1996) Sodium currents in thalamocortical neurones. Soc Neurosci Abstr 22:631.20.

Pedroarena C, Llinás R (1997) Dendritic calcium conductances generate high-frequency oscillation in thalamocortical neurons. Proc Natl Acad Sci USA 94:724-728.

Pirchio M, Turner JP, Williams SR, Asprodini E, Crunelli V (1997) Postnatal development of membrane properties and delta oscillations in thalamocortical neurons of the cat dorsolateral geniculate nucleus. J Neurosci 17:5428-5444.

Raman IM, Bean BP (1997) Resurgent sodium current and action potential formation in dissociated cerebellar Purkinje neurons. J Neurosci 17:4517-4526.

Ribary U, Ioannides AA, Singh KD, Hasson R, Bolton JPR, Lado F, Mogilner A, Llinás R (1991) Magnetic-field tomography of coherent thalamocortical 40-Hz oscillations in humans. Proc Natl Acad Sci USA 88:11037-11041.

Roy ML, Narahashi T (1992) Differential properties of tetrodotoxinsensitive and tetrodotoxin-resistant sodium channels in rat dorsal root ganglion neurons. J Neurosci 12:2104-2111.

Safronov BV, Vogel W (1995) Single voltage-activated $\mathrm{Na}^{+}$and $\mathrm{K}^{+}$ channels in the somata of rat motoneurones. J Physiol (Lond) 487:91-106.

Sah P, Gibb AJ, Gage PW (1988) The sodium current underlying action potentials in guinea pig hippocampal CA1 neurons. J Gen Physiol 91:373-398.

Saint DA, Ju, YK, Gage PW (1992) A persistent sodium current in rat ventricular myocytes. J Physiol (Lond) 453:219-231.

Sillito AM, Jones HE, Gerstein GL, West DC (1994) Feature-linked synchronization of thalamic relay cell firing induced by feedback from the visual-cortex. Nature (Lond) 369:479-482.

Silva LR, Amitai Y, Connors BW (1991) Intrinsic oscillations of neocortex generated by layer 5 pyramidal neurons. Science 251:432-435.

Steriade M, Jones EG, Llinás RR (1990) Thalamic oscillations and signalling. London: Wiley.

Steriade M, Dossi RC, Contreras D (1993) Electrophysiological properties of intralaminar thalamocortical cells discharging rhythmic $(\approx 40$
$\mathrm{Hz}$ ) spike-bursts at $\approx 1000 \mathrm{~Hz}$ during waking and rapid eye-movement sleep. Neuroscience 56:1-9.

Ströhmann B, Schwarz DWF, Puil E (1994) Mode of firing and rectifying properties of nucleus ovoidalis neurons in the avian auditory thalamus. J Neurophysiol 71:1351-1360.

Stuart G, Sakmann B (1995) Amplification of EPSPs by axosomatic sodium channels in neocortical pyramidal neurons. Neuron 15:1065-1076.

Sugimori M, Kay A, Llinás R (1994) The persistent $\mathrm{Na}^{+}$current in cerebellar Purkinje cells has a single channel conductance distinct from the inactivating current. Soc Neurosci Abstr 20:63.

Tennigkeit F, Schwarz DWF, Puil E (1996) Mechanisms for signal transformation in lemniscal auditory thalamus. J Neurophysiol 76:3597-3608.

Tóth TI, Crunelli V (1992) Computer simulation of the pacemaker oscillation in thalamocortical cells. NeuroReport 3:62-66.

Tóth TI, Crunelli V (1995) A numerical procedure to estimate kinetic and steady-state characteristics of inactivating ionic currents. J Neurosci Methods 63:1-12.

Tóth TI, Crunelli V (1996) The theoretical basis for non-exponential time-course of the recovery from inactivation of Hodgkin-Huxley-type ionic currents. Neuroscience 71:367-369.

Traub RD, Miles R (1991) Neuronal networks of the hippocampus. Cambridge, UK: Cambridge UP.

Traub RD, Wong RKS, Miles R, Michelson H (1991) A model of a CA3 hippocampal pyramidal neuron incorporating voltage-clamp data on intrinsic conductances. J Neurophysiol 66:635-650.

Turner JP, Anderson CM, Williams SR, Crunelli V (1997) Morphology and membrane properties of neurones in the cat ventrobasal thalamus in vitro. J Physiol (Lond) 505:707-726.

Williams SR, Turner JP, Anderson CM, Crunelli V (1996) Electrophysiological and morphological properties of interneurons in the rat dorsal lateral geniculate-nucleus in vitro. J Physiol (Lond) 490:129-147.

Williams SR, Turner JP, Hughes SW, Crunelli V (1997) On the nature of anomalous rectification in thalamocortical neurones of the ventrobasal thalamus in vitro. J Physiol (Lond) 505:727-747.

Zhou Q, Godwin DW, O'Malley DM, Adams PR (1997) Visualization of calcium influx through channels that shape burst and tonic firing modes of thalamic relay cells. J Neurophysiol 77:2816-2825. 